\title{
A USES AND GRATIFICATIONS STUDY OF
}

NICHE SOCIAL NETWORK SITES

A Thesis presented to
the Faculty of the Graduate School
at the University of Missouri-Columbia
In Partial Fulfillment
of the Requirements for the Degree
Master of Arts
by
SHILO WEIR
Mar. Margaret Duffy, Thesis Supervisor 2014


(C) Copyright by Shilo Weir 2014

All Rights Reserved 
The undersigned, appointed by the dean of the Graduate School, have examined the thesis entitled

\section{A USES AND GRATIFICATIONS STUDY OF}

NICHE SOCIAL NETWORK SITES

presented by Shilo Weir, a candidate for the degree of Master of Arts in Journalism and hereby certify that, in their opinion, it is worthy of acceptance.

Dr. Margaret Duffy, Committee Chair

Dr. Maria Len-Rios, Committee Member

Prof. Jonathon Stemmle, Committee Member

Dr. Melissa Click, Outside Committee Member 


\section{DEDICATION}

I dedicate this thesis to my perfect husband and two brilliant, beautiful daughters in return for their dedication to me.

And, of course, to the knitters. 


\section{ACKNOWLEDGEMENTS}

I would like to thank Doctor Margaret Duffy for taking on the position as chair of my committee with little to no prior knowledge of my ability. Thank you for agreeing to support me through the completion of my thesis. Moreover, thank you for giving me the freedom and confidence I needed to really make this thesis my own and for always having the answer I needed to make me feel at ease with the process.

I would also like to thank the rest of my thesis committee for their guidance, insight and expertise. Dr. Click, your observations were crucial to my ability to drive this thesis home. I would have missed some major impact without them. Dr. Len-Ríos, sharing your experience in quantitative methods really made a huge difference.

Professor Stemmle, thank you for your frankness in agreeing to participate in my committee out of curiosity to see how I was going to pull it off.

I owe a special debt and thanks to Sarah Smith-Frigerio. Your encouragement was a huge influence in completing this thesis and the program as a whole. You are a wise, dedicated instructor and a caring, inspirational advisor. Your commitment to the program and students did not go unnoticed. Thank you for everything. 
Acknowledgements...........................................................................................

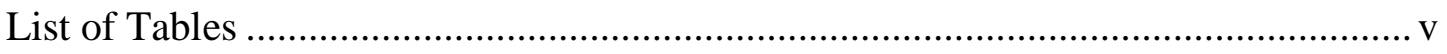

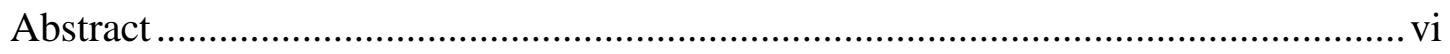

Chapter

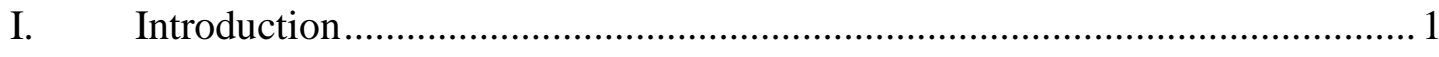

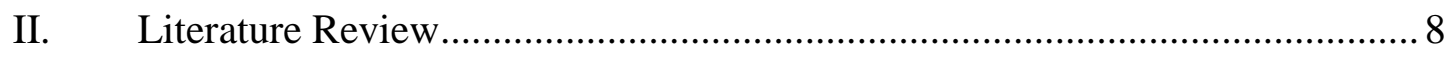

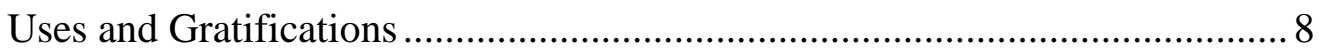

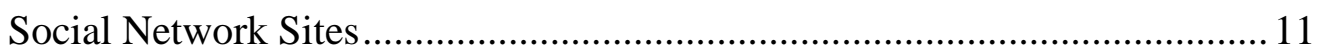

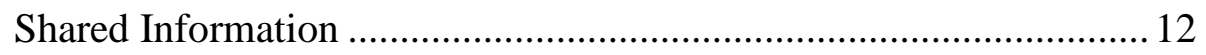

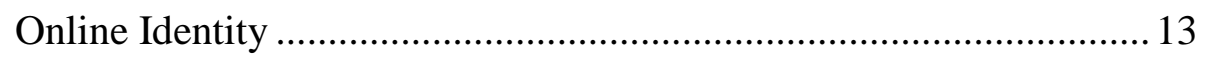

Relationships .............................................................................. 14

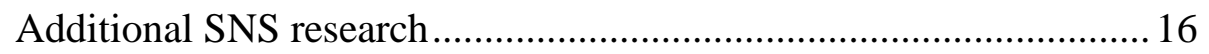

Uses and Gratifications of SNS ............................................................... 16

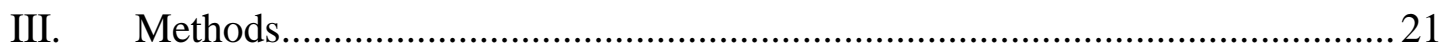

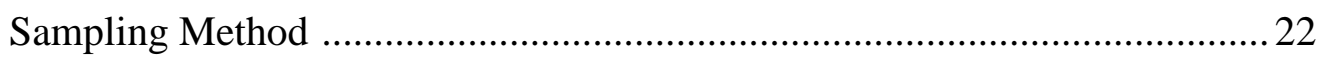

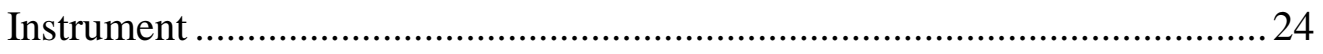

Sample Description .................................................................................... 28

Population and sample size.............................................................. 28

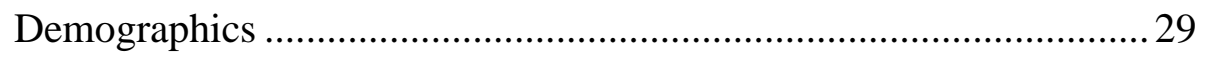

Social network site use habits ............................................................... 31

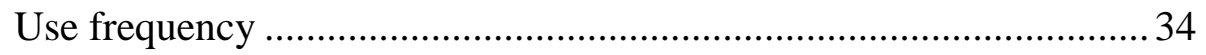




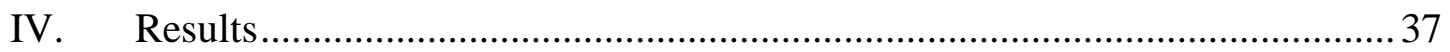

Social Network Site Use Motives ........................................................ 37

Ravelry Use Motives.............................................................. 37

Facebook Use Motives.............................................................. 39

Social Network Site Motives Compared.................................................. 41

Open-ended Reponses.................................................................... 46

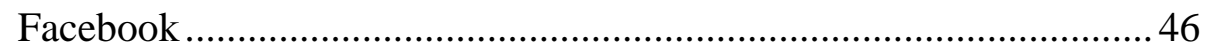

Ravelry .......................................................................... 48

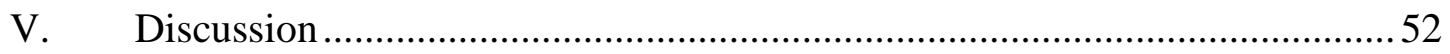

Limitations ........................................................................ 52

Implication and Future Research ................................................5 54

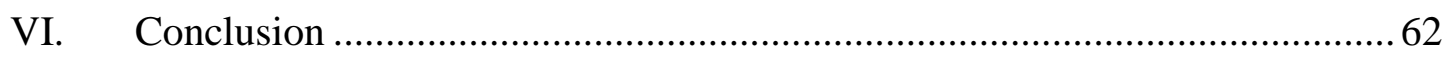

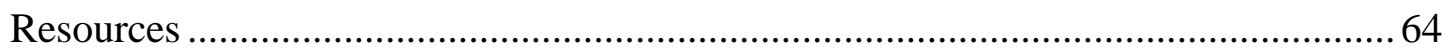

Appendix

A. Ravelry Moderator Permission ............................................................ 70

B. Survey Recruitment Message …............................................................ 71

C. Social Network Site Use Survey Instrument ......................................... 72

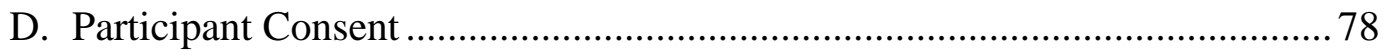

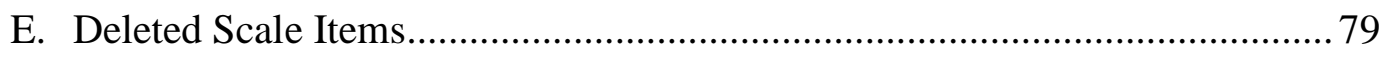




\section{LIST OF TABLES}

Table

Page

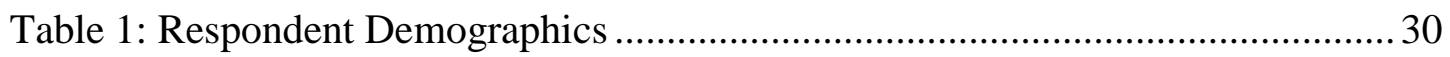

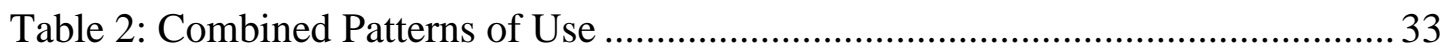

Table 3: Combined SNS Use Characterization......................................................... 36

Table 4: Summary of Ravelry Use Motive Factors and Items ................................38

Table 5: Summary of Facebook Use Motive Factors and Items .............................. 40

Table 6: Summary of Subscale Means \& Standard deviations ................................ 45 


\title{
A USES AND GRATIFICATIONS STUDY OF NICHE SOCIAL NETWORK SITES
}

\author{
Shilo Weir
}

\author{
Dr. Margaret Duffy, Thesis Supervisor
}

\begin{abstract}
This study applied the uses and gratifications theory to determine how audience motives for using niche social network sites compared with motives for using popular social network sites. An online survey presented a single sample $(\mathrm{N}=554)$ with items measuring motives for using the popular social network site Facebook alongside items measuring motives for using the niche social network site Ravelry for comparison.

The results demonstrate that there is a significant amount of overlap between the motives for Ravelry use and for Facebook use. The motives of relaxing entertainment, expressive information sharing, habitual pass time, social interaction, cool new technology, and professional advancement emerged during separate factor analyses of both the Ravelry and Facebook use motive scales. New friendships emerged only as a motive for Ravelry use. The results also showed the most salient motive for Facebook use was social interaction where the most salient motives for using Ravelry were relaxing entertainment and new friendships. The strongest motive for using Facebook related to relationships maintenance, which supports findings of past research. In contrast, Ravelry use motives show members are seeking new relationships through the niche social network site. Implications of the significant differences between motives for using the niche social network site and the popular social network site are discussed. Additional research is suggested to refine the current conceptual definition of social network site and to classify social network sites.
\end{abstract}




\section{Introduction}

Since its founding in 2004, Facebook has grown its population of active users to more than one billion as of December 2012 (“Facebook: Key facts,” n.d.). Such largescale participation in a website has drawn a great deal of attention; so much so, that Facebook was the subject of a hit movie in 2010 called The Social Network.

The popularity of social network sites has also captivated the research community. Researchers across disciplines have studied social network sites to try to understand the sites' makeup, impact, culture, meaning, and the people who use these sites (Acquisti \& Gross, 2006; Boyd \& Ellison, 2008).

The term social network site (SNS) generally refers to a website that allows users to create a network of connections to people with whom they wish to share profile information, news, status updates, comments, photos, or other forms of content (Steinfield, Ellison, Lampe, \& Vitak, 2012). Early definitions note that online SNSs are Internet communities where individuals interact through profiles presenting their public image and their networks of connections to others (Acquisti \& Gross, 2006).

Boyd and Ellison (2008) ascertained that SNSs have three distinct characteristics that separate them from other modes of computer-mediated communication. They found that SNSs are "web-based services that allow individuals to (1) construct a public or semi-public profile within a bounded system, (2) articulate a list of other users with whom they share a connection, and (3) view and traverse their list of connections and those made by others within the system” (p. 211). 
Hundreds of active social network sites meet these characteristics today. Popular SNSs like Facebook, Twitter, LinkedIn, Google+, and Flickr are open to the general population and attract millions of active members. According to Pew Research Center (2012), 67\% of online adults use social network sites (Duggan, 2012).

Boyd and Ellison (2008) observed that individuals often extend existing relationships into popular SNSs. For example, high school graduates might retain or reestablish connections using SNSs. Other SNSs connect strangers based on shared interests or activities. Although face-to-face relationships may be extended through their use, the present study posits that these other sites are more often aimed specifically at creating new connections between people with shared interests. Specifically, the present study looked at these other SNSs that target or draw niche audiences.

Of the hundreds of existing SNSs, a handful of niche SNSs maintain more than a million active users. An anecdotal examination of a list on Wikipedia provides examples of niche SNSs such as 43 Things, CafeMom, and Ravelry ("List of Social Networking Sites,” n.d.). Although more robust and popular SNSs are fully capable of connecting niche audiences, millions of users still have an affinity for sites that are off the beaten Internet path. The question remains as to why.

In 2008, David Beer published a response to Boyd and Ellison’s (2008) social network site definition. In this article, Beer (2008) recognized a pressing need to classify in order to arrive at a more descriptive analysis, considering the rapidly changing and shifting nature of online culture. However, he felt that Boyd and Ellison's definition was too broad and questioned, "why not stick with the vernacular terminology, social networking site, which is more differentiated and descriptive of the processes, rather than 
moving toward this re-definition forwarded in [B]oyd and Ellison's article?” (Beer, p. 519, 2008).

Boyd and Ellison's (2008) definition is used in research today and was unaffected by Beer’s (2008) observation. By learning more about how these niche sites are used by their members, researchers can determine whether they are truly SNSs or another genre of site with some SNS characteristics. Understanding the similarities and differences between popular and niche SNSs offers the opportunity to examine the current SNS definition, expands the understanding of the SNS audience, and also informs effective marketing strategies, advertising approaches, and the construction of niche social network sites that succeed.

There is a vast body of research on the most popular social network sites, like Facebook and Twitter, and their audiences. What has yet to be tested is whether niche social network sites and their audiences differ. In hopes of understanding niche social network sites and their users, the purpose of this study is to determine how audience motives for using niche social network sites compare to motives for using popular social network sites.

For the purposes of this study, a niche social network site is a website that meets the characteristics defined by Boyd and Ellison (2008) and allows users who share a common interest or activity (i.e. knitters, runners, educators, etc.) to create a network of connections with people they wish to share profile information, news, status updates, comments, photos, or other forms of content related to their shared interest or activity. Niche social network sites closely resemble an SNS description offered by Raacke and Bonds-Raacke (2008) which states that they are, "virtual places that cater to a specific 
population in which people of similar interest gather to communicate, share, and discuss ideas” (p. 169).

In contrast, popular social network sites, for lack of an existing distinction, are those SNSs that meet the characteristics defined by Boyd and Ellison (2008) and are open to the general public while not restricting membership outside of setting an age minimum, such as Facebook, Twitter, Google+, and the like.

Why distinguish niche social network sites? SNSs can vary in the extent to which they offer new information and communication tools to their users (Boyd \& Ellison, 2008). This may very well be the case with niche SNSs when compared to popular SNSs. This may also explain, for example, the motives that 3.4 million knitters, crocheters, designers, spinners, weavers, and dyers (“Ravelry People Search,” n.d.) have for using a specialized SNS versus just connecting with one another through an existing popular SNS like Facebook.

Although sites that cater to niche audiences meet the definition of SNS, characterizing them as such may be premature. As noted through my observations, the way users access niche SNSs can vary dramatically from one user to the next. For example, one user may access a site daily to check for new messages and see the recent activities of friends, while another may occasionally access the same site solely for functions outside communicating with other members.

Differentiating between popular and niche social network sites allows for a fuller understanding of the SNS user audience and prevents over-generalizations. In order to understand the SNS audience and why individuals use niche social network sites when 
popular sites are so readily available, this study addresses the following research questions:

RQ1: What are the motives for niche social network site use?

RQ2: What are the motives for popular social network site use?

RQ3: How do motives for using niche social network sites compare with motives for using a popular social network site?

A great deal of effort goes into advertising and marketing online each year. In spite of the many advanced options available to advertisers and marketers, effectively measuring the impact of efforts to advertise online is still challenging (Rodgers, Wang, Rettie \& Alpert, 2007). Rodgers et al. (2007) assert, “consumer motives for Internet use have been identified as a key to understanding the effectiveness of interactive advertising strategies” (p. 448). Marketers must have an understanding of social network site audiences before they can advertise effectively on these sites. This underscores the need to distinguish whether audience motives for using popular SNSs differ from those for using niche SNSs.

It is clear that the development of social network sites has added new dimensions to the way people communicate online. Answering the research questions aids in reaching the overarching goal: To understand what draws audience members to niche SNSs versus using existing popular SNSs.

The present study applied a uses and gratifications (U \& G) framework to examine what sets niche SNSs apart from popular SNSs. Since its introduction in the 1940s, researchers have used U \& G to understand what draws audience members to new media and content. The $U$ \& $G$ approach has a rich history of assisting in the pursuit of 
understanding why people use specific media and what people use media for (McQuail, 2000).

Uses and gratifications offers an appropriate means to examine niche social network sites. Notable examples of historic U \& G research included studies pointed at understanding the audiences of radio soap operas, quiz shows, and newspaper (Katz \& Foulkes, 1962). While U \& G has been used to examine popular social network sites (i.e. Park, Kee, \& Valenzuela, 2009; Quan-Haase \& Young, 2010; Raacke \& Bonds-Raacke, 2008; etc.), it has yet to be used specifically to explore niche social network sites. The U \& $G$ framework assumes that (a) audience members are active and selective, (b) they are goal-oriented and aware of their needs, and (c) they select their particular type of media and content to satisfy those needs (Kaye \& Johnson, 2002; McQuail, 2000; Ruggiero, 2000).

Survey research was used to collect data directly from a niche SNS audience about their use of both the niche site Ravelry and the popular SNS Facebook. The uses and gratifications framework allows this study to answer the research questions, develop a better understanding of the SNS audience, and determine where uses of niche and popular SNSs diverge. The methods section of this thesis provides a detailed outline of this approach. Aside from adding to the body of research on social network sites, the results validate the need to differentiate between the popular and niche SNS audiences and the need to differentiate between the sites themselves.

This thesis does the following: (a) outlines the uses and gratifications theory and its application in the present study; (b) reviews the existing research on social network sites; (c) provides a detailed explanation of the research methods; (d) demonstrates how 
U \& G was used to uncover audiences motives for using niche social network sites; and, (e) discusses the limitations, implications, and conclusions drawn from this study.

Extant literature and research regarding social network sites offers fertile ground for further research into SNSs. The first step in understanding the importance of social media use is determining what motivates audiences to use this medium. McQuail (1984) said it best, "what is central for mass communication is not message-making or sending and not even the messages themselves, but the choice, reception and manner of the audience” (p. 184). 


\section{Literature Review}

\section{Uses and Gratifications}

The uses and gratifications ( $U$ \& $G$ ) theory has a long history dating back as far as the 1940s (McQuail, 2000). The study of media use began with the simple attempt to understand the appeal of popular radio programming. This approach has provided insight into what draws audience members to new media and content. Notable examples of historic U \& G research include attempts to understand why women listened to radio soap operas, the gratifications provided through quiz shows, the functions served by newspaper reading, and the motives behind listening to serious music on the radio (Katz \& Foulkes, 1962). In the past, U \& G theory has provided a “cutting-edge theoretical approach in the initial stages of each of the mass communications medium” (Ruggeiro, 2000, p. 27).

Scholars have examined many conventional media over the past 70 years, such as radio, newspapers, television, and the telephone to name a few (Ruggeiro, 2000). A crucial turning point for $U$ \& $G$ research came with the publication of the article "Mass Communication Research and the Study of Culture,” by Elihu Katz in 1959 (McQuail, 1984). In this article, Katz asserted:

[L]ess attention [should be paid] to what media do to people and more to what people do with the media. Such an approach assumes that even the most potent of mass media content cannot ordinarily influence an individual who has no use for it (McQuail, 1984, p. 178).

Because of Katz's work, the theory saw a surge in research in the 1960s and early 1970s (McQuail, 2000). Research maintained focus on the idea of the active audience 
with a concentration on the gratifications sought (Ruggeiro, 2000). Throughout the 1970s, U \& G researchers spent an increased amount of time examining audience motivations and developing typologies of the ways people used media to gratify social and psychological needs (Ruggeiro, 2000). This subset of research did not provide a refined theoretical perspective. However, Ruggiero (2000) contended that a typology of uses gives researchers, “a benchmark base of data for other studies to examine further media use” (p. 12). Thereafter, typologies have been invaluable in helping researchers to better understand audience members and predict their behavior.

The testing and refinement of use and motive typologies have continued in modern U \& G research. For example, McQuail (2000) proposed the following as motives for audience use of radio and television programming (p. 388):

- Diversion: escape from routine or problems; emotional release

- Personal Relationships: companionship; social utility

- Personal identity: value reinforcement; reality exploration; self-reference

- Surveillance: information seeking

Even more recently, uses and gratifications theory has been used to examine new media and computer-mediated communication as the Internet grows and accessibility becomes more widespread. The rapid expansion of the World Wide Web provided users with a wider range of sources to choose from, and in turn provided researchers with a wider range of phenomena to examine. The following are select examples of studies that use a variety of use motive typologies to apply uses and gratifications theory to new media.

Kaye and Johnson (2002) studied the Internet and the uses and gratifications of accessing political information from online sources. They surveyed more than 300 respondents to assess their motives for use. Their findings suggest that reasons for 
accessing political websites could be categorized under four motives: guidance, information seeking/surveillance, entertainment, and social utility (Kaye \& Johnson 2002).

Papacharissi and Rubin (2000) identified five motives that predict Internet use. Their analysis identified interpersonal utility, passing time, information seeking, convenience, and entertainment as motives. Additionally, Kaye (2005) identified six motives in the study of blog readers: information seeking and media checking, convenience, personal fulfillment, political surveillance, social surveillance, expression, and affiliation.

As new communication technologies continue to grow, users are given more media options than ever before. Researchers have explored the $U$ \& $G$ of the Internet and computer-mediated communication in a variety of different contexts. Some examples of contextual approaches in online media included: the World Wide Web (Flanagin \& Metzger, 2001; Kaye \& Johnson, 2002; Korgaonkar \& Wolin, 1999), the Internet (Papacharissi \& Rubin, 2000; Parker \& Plank, 2000), and personal home pages (Papacharissi \& Rubin, 2000).

Motives for using the Internet span both interpersonal and mass communication situations. Many researchers have made the specific distinction between use motives that are traditionally associated with mass communication (i.e. entertainment, surveillance, passing time) and those associated with interpersonal communication (i.e. social interaction, identity) (Kaye \& Johnson, 2002; Papacharissi \& Rubin, 2000; Tewksbury \& Althuas, 2000). The Internet has advanced the potential of human communication by offering a mixture of uses and gratifications in one place that were only obtainable 
through multiple mediums in the past. The uses and gratifications theory offers the opportunity for understanding the uses of social network sites and the communication situations found therein.

\section{Social Network Sites}

Computer-mediated communication (CMC) is communication facilitated by computer technologies (Papacharissi \& Rubin, 2000). This type of communication comes in many forms online such as e-mail, bulletin boards, chat rooms, computer conferencing, blogs, and now social network sites. Social network sites offer a combination of features from their predecessors making them an object of increasing attention. A great deal of research has been done over the past 20 years on the many forms of computer-mediated communication. Research focusing on SNSs, despite the attention they have received, is still relatively limited but growing rapidly.

The historic roots of social network sites reach back to 1997 (sixdegrees.com) (Acquisti \& Gross, 2006; Boyd \& Ellison, 2008). The earliest SNS research focused on understanding the social network site makeup. These approaches included examinations of their basic capabilities such as how profiles are constructed, how connections are made, and what other communication features are available (Steinfield, et al., 2012). Further research examined SNSs from a number of approaches including ethnographic and sociological examinations of online self-representation; discussions of information sharing and privacy within online social networks; marketing value of online social network technology; research on how information revealed in social networks can be exploited; and, identity-sharing behavior in online social networks (Acquisti \& Gross, 2006). 
The bulk of current research seems to fall into three broad categories of study. Within the context of social network sites, researchers have been examining the information shared, the ways people use their online identities, and the relationships between users. Examination of these categories reveals both some limitations in existing research as well as areas for further research.

Shared Information. The majority of research into shared information on social network sites has focused on the types and amount of personal information shared by site members and questions the potential impact on privacy and personal security. For example, much of this research area examines the potential for identity theft. Other work attempts to explain why users are willing to reveal such personal information on social network sites when they would normally seek to protect their privacy on the Internet (Acquisti \& Gross, 2006; Dwyer, Hiltz \& Passerini, 2007; Stutzman, 2006).

Online privacy and personal security are significant concerns in an age where credit card and identity theft are legitimate threats. Many characteristics of SNSs make them gold mines of personal information. The information users share in updates, photos, and profiles has been seen as potentially harmful to users. For example, Foursquare.com is a location-based SNS that allows users to "check-in" and publicly share where they are located and save where they have been. In 2010, a number of hackers and media exposed the privacy concerns associated with posting one’s location at any given time (McCarthy, 2010). This highlighted the fact that a Foursquare user's movements could easily be tracked and monitored using the site, increasing the user's risk of being victimized. Research has approached this type of study of shared information on SNSs in a number of different ways. 
Initially, this line of research looked at whether the information revealed online posed a threat to privacy and safety (Gross \& Acquisti, 2005; Lenhart \& Madden, 2007; Stutzman, 2006). Other studies have examined the relationship between the information users share on SNSs and their reported views on privacy concerns (Acquisti \& Gross, 2006; Dwyer et al., 2007). Dwyer et al. (2007) found that Facebook members expressed significant trust in both Facebook and its members. Further, their conclusions suggest that members are more trusting online than they would be in new face-to-face relationships. Acquisti and Gross (2006), using a combination of data mining and survey research, found that SNS members who reported being concerned with privacy issues significantly misunderstood the actual size and composition of online communities and the visibility of the information in their own member profiles.

Online Identity. The next concentrated area of research into social network sites sought to understand how people use and create their online identities. Research into online SNS identities examined the creation of online personas, how users manipulate their profiles, and how members use aspects of profiles to influence friendships and manage impressions (Boyd, 2008; Boyd \& Heer, 2006; Tong, Van Der Heide, Langwell \& Walther, 2008; Walther, Van Der Heide, Kim \& Westerman, 2008). This research studied how individuals use SNS features and technology to build and maintain the image they wish to project online.

Boyd (2008) examined why teenagers like social network sites and the role the sites play in modern social development. The study found that teens were using this venue to learn how to interact with people with whom they were less familiar and that SNS interactions were playing an important role in how teens developed their social 
identities. Similar studies have examined how SNS members use and manipulate their online profiles to experiment with and build identities online, both real and fake (Boyd \& Heer, 2006; DiMicco \& Millen, 2007). In 2012, a widely reported hoax involving then Notre Dame linebacker Manti Te’o and a fictitious woman he dated on Facebook garnered international attention and displayed the issues, complexities, and unique nature surrounding online identities.

Another aspect of online identities explored in SNS research looked at how members use profiles when making judgments about their impressions of the identities of others. Lampe et al. (2006) found that SNS members use online profiles to investigate people they met in person. The researchers described this behavior as social browsing. In another approach to this same type of investigation into social browsing, Tong et al. (2008) conducted an experiment to determine the extent that SNS features (i.e. number of friends, profile contents, etc.) are used by onlookers to judge popularity and social attractiveness. The attractiveness and behaviors of one's friends is another aspect of SNSs used by onlookers to pass impression judgments on one another's online identities (Walther et al., 2008). These aspects of impression management and the impact that an owner's profile has on the identity they project leads users to manipulate and sculpt the online impression they wish to depict - even if it means an inaccurate or fictitious representation of the owner's offline identity (Boyd \& Ellison, 2008).

Relationships. Research into the relationships between users on SNSs looked at the structure of the connection networks built by users (Hogan, 2008; Liben-Nowell, Novak, Kumar, Raghavan \& Tomkins, 2005). An additional focus in this area explored the nature of the connections people made within SNSs. Many studies argued that sites 
like Facebook are used to extend or maintain existing offline relationships (Choi, 2006; Ellison, Steinfield \& Lampe, 2007; Lampe, Ellison, \& Steinfield, 2006) instead of building new relationships as many had speculated in both the academic community and the popular press.

The development of virtual communities within various modes of computermediated communication has been a focus of the popular press and scholarship. Research into SNSs is no exception. However, studies have found that the majority of relationships in social network sites were initiated offline and in person (Ellison et al, 2007; Ellison, Steinfield \& Lampe, 2009; Lampe et al., 2006; Subrahmanyam et al., 2008). Lampe et al. (2006) set out specifically to investigate this aspect of SNS online relationships. They found that people were "using Facebook as a surveillance tool for maintaining previous relationships, and as a ‘social search' tool with which they investigate people they've met offline” (p. 170).

Most other research regarding online connections within SNSs started with a different primary investigative focus, but the emerging results demonstrated that the majority of users were not seeking to meet new people on these sites. This research essentially showed that users are maintaining and building existing relationships with friends and family in this venue. Ellison et al., (2007) found that online interactions do not remove people from their offline networks, but are used to support relationships and keep people in contact. This finding further demonstrates that SNSs may play a role different from that described in early literature on virtual communities.

A large trend in research on relationships in SNSs is the study of various aspects of social capital. Steinfield et al. (2012) defined social capital as "the accumulated 
resources derived from the relationships among people within a specific social context or network" (p. 3). Researchers have explored how social capital is built, maintained, and manipulated on SNSs and its impact on users.

Building on their earlier research on social capital, Ellison, Steinfield and Lampe (2011) explored how SNS users perceived differences between real and Facebook friends and how SNS members use online connections to manage social capital. The findings of this study suggest that SNSs play an important role in helping college students maintain social networks and develop the social capital that is embedded within them. The researchers felt that communication practices within an SNS impact social capital outcomes and underscore the importance of examining not just whether individuals use a particular site, but what they do with it (Ellison, et al., 2011).

Additional examples of research on social capital in social network sites include how the SNS medium affects social capital processes (Ellison, Lampe, Steinfield \& Vitak, (2010), how SNSs and social capital affect a professional organization (Steinfield, DiMicco, Ellison \& Lampe, 2009), and how social capital in SNSs use can affect selfesteem (Steinfield, Ellison, \& Lampe, 2008).

Additional SNS research. In addition to the research areas identified above, there is a growing body of research into other aspects of social network sites. This scholarship focuses on unique SNS population subgroups (Boyd \& Ellison, 2008). Research on population subgroups has included examinations of SNS members based on religion, race, ethnicity, and sexuality.

\section{Uses and Gratifications of SNS}

Social network sites are relatively nascent forms of communication technology. 
Research, while prolific, is still in its infancy when compared to other modes of computer-mediated communication. Because of this, it is not surprising that examinations of SNSs using uses and gratifications theory are limited. In social network site research, the "benchmark of base data" that Ruggiero (2000) suggested would come from applying the uses and gratification approach has yet to be seen (p. 12). Additionally, existing research focuses on the most popular SNSs because of their size and popularity. These studies largely look at how audiences are using Facebook. Facebook has been an obvious focus for much of the research examining SNS use (Steinfield, et al., 2012).

Sheldon (2008) pointed out “[a]s college students spend more time online than each generation before, it is important to know the gratifications they seek and obtain from the new media” (p. 39). Though this is true, most studies of Facebook to date have collected data on college student uses for two reasons. First, the earliest Facebook research focused on college populations because the site was restricted to student audiences until late 2006. Second, research at academic institutions is often limited to convenience samples of the student population.

Sheldon (2008) studied the uses and gratifications of Facebook by surveying 172 college students. The objective of this research was to see what students' motives were for using Facebook, how individual differences related to motives for Facebook use, and to what degree motives and individual characteristics can predict the attitude and behavior outcomes of Facebook use. This study used demographic information such as gender, age, and education level to predict Facebook use motives. In this U \& G approach, the study found that people go to Facebook to meet needs that are traditionally met through other media; however, they seek to fulfill their interpersonal communication 
needs first (relationship maintenance). Sheldon (2008) found, “most students go to Facebook to maintain relationships with people they know” (p. 40).

In another early study of Facebook uses by college students, Joinson (2008) investigated the uses of the site and the gratifications derived from those uses. This research identified seven unique use motives: social connection, shared identities, content, social investigation, social network, surfing, and status updating. Again, demographic information was used to evaluate the predictability of Facebook use motives. Users derive a variety of gratifications from SNSs, including traditional content gratification as well as building social capital, communication, surveillance, and social network. One distinction in this study was the added measure of patterns of Facebook use. For example, increased frequency of use was positively correlated with seeking social connection gratifications.

In a more recent approach to studying the uses and gratifications of Facebook, Papacharissi and Mendelson (2011) surveyed 344 college students to discern how they use this popular SNS. Prevalent motives that were uncovered included habitually passing the time and relaxing entertainment. Overall, this study found that motives for Facebook use furthered the notion that SNSs offer uses that converge from traditional and new media such as the escapism and companionship typically found in television use and the information seeking and career advancement seen in Internet use.

Papacharissi and Mendelson (2011) added open-ended questions to their approach to ensure uses were not overlooked. Open-ended responses helped the researchers determine that users perceive Facebook as helping them to "relieve boredom or distract them from or relieve them of daily stresses” (p. 19). Additionally, responses to the open- 
ended questions supported the researchers' interpretations of the quantitative data. The study indicated that participants "stressed” that they rely on Facebook for staying connected to those they already know. Participants valued Facebook for helping them keep up with people at a distance and keep others updated.

As with much of the previously mentioned studies on SNSs, Papacharissi and Mendelson (2011) found that users are able to fulfill traditional mediated and interpersonal needs simultaneously, stating that Facebook's “relaxing entertainment ... provided a way in which Facebook became useful for the generation of bonding social capital, thus reaffirming users' ties and connections to their close sphere of family and friends” (p. 21).

Throughout the research on the uses of Facebook and popular SNSs, two themes seem apparent: first, people use Facebook to build and maintain relationships and connections with people they already know; second, motives for use are made up of a combination of uses seen in both traditional media (i.e. television, newspaper, radio, etc.) and new media (computers, the Internet, chat rooms, etc.) (Joinson, 2008; Papacharissi \& Mendelson, 2011; Sheldon, 2008; Urista, Dong, \& Day, 2009). It remains undetermined whether the motives for use of niche SNSs can be distinguished from the motives for using popular SNSs.

Sites that the present study would define as niche social network sites are mentioned throughout the literature, but often only in passing to recognize that they exist. For example, Boyd and Ellison’s (2008) only mention of sites that cater to niche audiences is as follows:

"While most SNSs focus on growing broadly and exponentially, others explicitly seek narrower audiences. Some, like aSmallWorld and 
BeautifulPeople, intentionally restrict access to appear selective and elite. Others--activity-centered sites like Couchsurfing, identity-driven sites like BlackPlanet, and affiliation-focused sites like MyChurch--are limited by their target demographic and thus tend to be smaller” (p. 218).

This characterization exemplifies a lack of attention paid to niche SNSs.

The examination of existing literature here shows a Facebook-heavy approach to the study of social network sites. Because niche SNSs draw smaller and very specific audiences, researchers have passed them up in favor of popular SNSs that attract broad swaths of demographically-diverse users. This approach made sense as popular SNSs offered a richer research environment when SNS technology first gained popularity. However, this focus on popular sites has led to the creation of a body of knowledge dominated by studies of Facebook and Twitter. Further, typical studies focused largely on college student use of the sites. Currently, some niche sites are drawing a massive user base and the time is ripe for seeking deeper understanding of why people join niche SNSs. Understanding how audiences use niche social network sites can be used to uncover the potential significance that may go unseen in research focused solely on popular sites. 


\section{Methods}

The following section describes the research methods employed during this study. To reiterate, the purpose of this study is to determine how audiences use niche social network sites by answering the following questions: (RQ1) what are the motives for niche social network site use?; (RQ2) what are the motives for popular social network site use?; and, (RQ3) how do the motives for niche social network sites use compare with motives for using popular social network sites?

To address the research questions, it was necessary to identify two social network sites in order to collect the material necessary for a comparison. As seen in the review of literature, studies have primarily investigated how audiences use Facebook as it is by far the largest SNS worldwide, having surpassed the once popular MySpace in 2008 (Steinfield, et al., 2012). Under these circumstances, it makes sense to use Facebook as the choice popular SNS here.

In order to support this study's purpose, it was also necessary to call on a single niche social network site as the starting point for discovery. The website Ravelry.com offers features that make it useful as such a starting point.

Ravelry offers a unique SNS environment that varies from that of popular social network sites. Ravelry describes itself as:

[A] place for knitters, crocheters, designers, spinners, weavers and dyers to keep track of their yarn, tools, project and pattern information, and look to others for ideas and inspiration. The content here is all user-driven; we as a community make the site what it is. Ravelry is a great place for you to keep notes about your projects, see what other people are making, find the perfect pattern and connect with people who love to play with yarn from all over the world in our forums. (“Ravelry About Us," n.d.). 
Although Ravelry.com calls itself a community, it is clear from the description that it offers much more. The distinction from popular SNSs is notable. Humphrey (2009), in his research on economies within an online social network market, recognized that Ravelry not only meets Boyd and Ellison’s (2008) requisite standards for being a social network site but also adds the ability to track the connections between objects and people. By this standard, Ravelry is a database for tracking and sharing the many things associated with the fiber crafts such as projects, yarn, tools, and patterns all built into a social network site.

The most well known popular social network sites, Facebook, Twitter, and LinkedIn, serve approximately 1 billion, 500 million, 200 million users respectively (“List of Social Networking Sites,” n.d.). These numbers are vastly different from the numbers of users found on the sites that serve niche markets. Ravelry is a niche social network site that caters to fiber crafters and has seen a dramatic increase in membership since its creation in 2007. The site's membership continues to grow; it exceeded 3million members on March 8, 2013. Ravelry’s apparent success with a niche audience and the diverse features the site offers to members make it an optimal choice for discovering the prominent motives for using niche SNSs in comparison to the uses of popular sites.

\section{Sampling Method}

The ability to sample directly from the Ravelry population provides a unique situation. As seen in past studies, most studies of popular SNSs to date have collected data using "convenience” samples made up of available college students (Wimmer \& Dominick, 2011, p. 92). The present study had the opportunity to draw a sample directly 
from the niche SNS user population and use a sampling method that most closely resembles “snowball sampling” (Stacks, p. 204, 2011). Though both convenience and snowball produce non-probability samples, this variation in approach from previous research into SNSs provides a more adequate representation of the characteristics of the population in question than a convenience sample.

Sampling Ravelry users directly had some limitations. Efforts to contact Ravelers and request their participation in this study had to be coordinated and approved through the site's management. The obvious objective was to use a method that produced the least amount of sampling error. Drawing a simple random sample from the Ravelry population was not possible, as doing so would have violated the website’s policy on "spam" (“Ravelry Community Guidelines,” 2009).

Following the published policies regarding spam set under the Ravelry community guidelines (2009), the researcher obtained permission from a group moderator (see Appendix A) and then posted an invitation to participate in the study to a Ravelry Main 6 board entitled Loose Ends (see Appendix B). The Main 6, as they are referred to on the site, are discussion boards located inside the SNS that are automatically made available to every Ravelry member upon joining the site. A link to the invitation was also shared by Ravelry users themselves in a variety of settings. To the best of my knowledge, a dyer shared the invitation on her personal Ravelry board, a yarn store proprietor shared the link through Facebook and the board moderator tweeted a link to the Ravelry invitation. The full extent to which the invitation was shared is not known. Researchers have had success garnering adequate sample sizes using snowball samples when studying other Internet-based communication. The approach used in the 
present study is similar to what Kaye (2010) did when eliciting 1,989 responses by posting a survey link to several blogs asking for participation from readers.

\section{Instrument}

Social network sites can vary in the amount and type of content and unique tools they offer users (Boyd \& Ellison, 2008). This, in part, may explain the motives so many fiber crafters (knitters, crocheters, designers, spinners, weavers, and dyers) have for using this specialized venue. The present study applied a uses and gratifications (U \& G) framework to examine what sets Ravelry use motives apart from the motives for using Facebook through survey data collection. Since its introduction in the 1940s, U \& G theory has been used repeatedly to understand what draws audience members to new media and content. Further, in the U \& G effort to understand why people use media and what they use it for, the survey has been a key tool in finding answers (McQuail, 2000).

Survey research has aided in understanding the $U$ \& $G$ gained from a number of new media. In one example, Perse and Dunn (1998) used a random national telephone survey of 1,071 adults to understand how and why people use home computers.

Papacharissi and Rubin (2000) surveyed 279 college students when they set out to predict Internet use. In 2010, this method of data collection proved valuable when Kaye (2010) surveyed an impressive 1,989 blog readers to understand their motivations. There are hundreds of modern examples of surveys employed in U \& G research. Surveys have been used in researching new media uses in a variety of context: the World Wide Web (Kaye \& Johnson, 2002), personal home pages (Papacharissi, 2002), and Facebook (Papacharissi \& Mendelson, 2011; Park, et al., 2009; Sheldon, 2008) to name a few. 
Additionally, the best way to learn how and why members use Ravelry is to go straight to the source.

In reviewing the available uses and gratifications research conducted on popular SNSs, one study stood out for its efforts to create a typology of uses by combining interpersonal, media, new media and professional development motives and adapting measures used in past research on Facebook (Papacharissi \& Mendelson, 2011). Papacharissi and Mendelson’s (2011) scale for measuring Facebook use motives was adapted for use in the current comparison between the popular SNS Facebook and the niche SNS Ravelry. Papacharissi and Mendelson (2011) set out to study how motives and social-psychological traits affect Facebook use, social network structure, and social capital. In doing so, they compiled and adapted statements from past research to construct a scale of 11 potential motives for use. Although their research took a deeper look into the sociability of Facebook, they collected data on SNS uses, patterns of use, and demographics that can be used here to address the present study's purpose and research questions.

Smock et al. (2011) used the scale developed by Papacharissi and Mendelson (2011) in their effort to explore motives for using specific features of Facebook. This study confirmed the findings from the original use of the scale and was able to bring more clarity to "who is using what tool to what end" (Smock et al., 2011, p. 2328). The researchers examined the use of selected Facebook features - including status updates, comments, wall posts, private messages, chat, and groups - and found a more detailed explanation of how motivations are related to use that was not seen in the previous employment of the scale in a study of general Facebook use. Smock et al. (2011) 
identified the same motives for using Facebook as Papacharissi and Mendelson (2011) and pinpointed which features accounted for each of the use motives. This additional test of the scales' usefulness and reliability added to the appeal of using it in the present study.

This instrument developed by Papacharissi \& Mendelson (2011) measured 11 Facebook use motive categories: pass time, relaxation, entertainment, information sharing, professional advancement, companionship, social interaction, cool and new technology, self-expression, habit, and escape.

The present study measured two main constructs: Facebook use motives and Niche SNS use motives. The single sample drawn from the Ravelry audience was presented with statements measuring Facebook use motives alongside Niche SNS use motives, providing the means for the present study to collect the data necessary for addressing each of the research questions. The survey instrument consisted of five portions. The first portion contained questions designed to measure individual Ravelry members' motives for using the site. Using survey questions based on the 11 use motives found in Papacharissi and Mendelson (2011) and their subsequent recommendations, data was collected to answer RQ1 that was specifically intended at uncovering niche SNS use motives.

Papacharissi and Mendelson’s scale provides a measure that has proven valid and reliable in past research (2011). However, as recommended by both Papacharissi and Mendelson (2011), and Smock et al. (2011), the present survey expanded two motives from the original scale. The motive of "social interaction" was split in the original study to represent two motives: "social interaction” and "meet new people.” These new motives 
were measured on the original scale with a reduced number of items when compared to the remaining motives. The resulting motive of "meet new people” was considered a significant social motive for SNS use by researchers but did not meet the criteria for inclusion in statistical analysis in the past studies.

The present study represented each of the now 12 potential use motives with three items on the survey. Using software functions available, the Ravelry use motive statements in this section of the instrument were presented to respondents in random order to reduce the possibility of “question contamination” and bias (Wimmer \& Dominick, 2011, p.198).

Next, section 2 of the instrument contained questions used to gather data about the respondents Ravelry use habits (i.e. log in frequency; communication activities; number of friends, etc.).

Sections 3 and 4 of the survey instrument asked the respondents questions about their motives for using Facebook and Facebook use habits in the same manner in which they were questioned about their motives for using Ravelry and Ravelry use habits in the preceding two sections.

As seen in the example set by Papacharissi and Mendelson (2011), the survey instrument added a total of six open-ended questions - three regarding Ravelry and three regarding Facebook - to ensure that any uses unique to the selected niche and popular SNS were not overlooked. As suggested by Song, Larose, Eastin, and Lin, (2004), "new” gratifications sought by Internet users illustrate shortcomings in existing U \& G constructs that were developed in past investigations. 
The last portion of the survey gathered demographic information by asking respondents to report such information as their age, gender, highest grade-level completed, and annual income. A copy of the survey instrument can be found in Appendix C.

The survey instrument was administered using the online survey program Qualtrics that was available to the researcher through an existing license owned by University of Missouri, Columbia. Because Ravelry members were recruited directly through the site, it was efficient to make the survey available and easily accessible by simply clicking a link. The link to the survey was active and accepted responses between October 20 and November 19, 2013.

\section{Sample Description}

Population and sample size. The population for this study is the total number of registered Ravelry members. As of October 20, 2013, when the survey link was activated and made available, the population was made up of 3,491,705 knitters, crocheters, designers, spinners, weavers, and dyers ("Ravelry People Search,” n.d.). The only criteria for inclusion was that the respondent be a Ravelry member, a Facebook member and be over the age of 18 for reasons of consent. A copy of the study consent form is located at Appendix D.

Six-hundred ninety-two people began the online survey. Of those 692, 111 participants dropped out prior to completing the survey and an additional 27 cases were deleted listwise for missing data, leaving a total of 554 study participants and a completion rate of 80 percent. 
The present study used criteria recommended by Wimmer and Dominick (2011) to determine whether the sample size was adequate. Because sampling error cannot be calculated for non-probability samples, the following guidelines recommended for multivariate studies were used: “50 = very poor; 100 = poor; 200 = fair; 300 = good; 500 = very good; $1000=$ excellent” (p. 103). According to these criteria, the sample size is considered "very good" (p. 103).

Demographics. Of the 554 participants, 542 were female $(97.8 \%$ of the total respondents), and 12 were male (2.2\% of the total respondents). Survey respondents ranged in age from 18 to over 65 and included 28 respondents ages 18 to 24 (5.1\%) and 22 participants age 65 or older (4\%). More than $75 \%$ of respondents reported their age as between 25 and 54 years old. The largest age group included 152 respondents age 35 to 44 year olds (27.4\%).

As for respondents level of education, more than $80 \%$ of the respondents had completed at least a 2-year College Degree. This included 211 respondents with 4-year College Degrees, 140 (25.3\%) respondents who reported “Master’s Degree”, 37 (6.7\%) respondents with “Doctoral Degree”; and, 30 (5.4\%) with "Professional Degree” such as a medical or law degree.

Eighty-eight respondents (15.9\% of total respondents) earn below \$20,000 annually; 44 (7.9\%) earn \$20,000 - \$29,999; 43 (7.8\%) earn \$30,000 - \$39,999; 60 (10.8\%) earn \$40,000 - \$49,999; 66 (11.9\%) earn \$50,000 - \$59,999; 48 (8.7\%) earn $\$ 60,000$ - \$69,999; 33 (6\%) earn \$70,000 - \$79,999; 27 (4.9\%) earn \$80,000 - \$89,999; 99 (17.9\%) earn $\$ 90,000$ or more; and 46 (8.3\%) indicated that they prefer not to provide information about their annual income. 
Two-hundred fifty-four respondents (45.8\% of total respondents) were employed full-time and 87 (15.7\%) were employed part-time. Of the remaining 38.5\% of respondents, 41 (7.4\%) were students; 56 (10.1\%) were retired; 23 (4.2\%) were unemployed, but seeking employment; 48 (8.7\%) reported being unemployed by choice; and, 45 (8.1\%) reported their employment status as “other.”

The complete demographics of this sample are available in Table 1.

Table 1: Respondent Demographics

\begin{tabular}{|c|c|c|}
\hline$N=554$ & Frequency & Percentage \\
\hline \multicolumn{3}{|l|}{ Age } \\
\hline 18 to 24 years & 28 & 5.1 \\
\hline 25 to 34 years & 132 & 23.8 \\
\hline 35 to 44 years & 152 & 27.4 \\
\hline 45 to 54 years & 132 & 23.8 \\
\hline 55 to 64 years & 88 & 15.9 \\
\hline 65 years and over & 22 & 4.0 \\
\hline \multicolumn{3}{|l|}{ Gender } \\
\hline Male & 12 & 2.2 \\
\hline Female & 542 & 97.8 \\
\hline \multicolumn{3}{|l|}{ Education Level } \\
\hline Some High School & 3 & .5 \\
\hline High School / GED & 16 & 2.9 \\
\hline Some College & 76 & 13.7 \\
\hline 2-year College Degree & 41 & 7.4 \\
\hline 4-year College Degree & 211 & 38.1 \\
\hline Master's Degree & 140 & 25.3 \\
\hline Doctoral Degree & 37 & 6.7 \\
\hline Professional Degree (JD, MD) & 30 & 5.4 \\
\hline \multicolumn{3}{|l|}{ Annual Income } \\
\hline Prefer not to answer & 46 & 8.3 \\
\hline Below $\$ 20,000$ & 88 & 15.9 \\
\hline$\$ 20,000-\$ 29,999$ & 44 & 7.9 \\
\hline$\$ 30,000$ - \$39,999 & 43 & 7.8 \\
\hline$\$ 40,000-\$ 49,999$ & 60 & 10.8 \\
\hline$\$ 50,000-\$ 59,999$ & 66 & 11.9 \\
\hline$\$ 60,000$ - \$69,999 & 48 & 8.7 \\
\hline$\$ 80,000-\$ 89,999$ & 27 & 4.9 \\
\hline$\$ 90,000$ or more & 99 & 17.9 \\
\hline
\end{tabular}


$\$ 70,000-\$ 79,999$

Employment Status

Employed Full-time

Employed part-time

Student

Retired

Unemployed, but seeking employment.

Unemployed by choice

Other
33

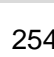

87

41

56

23

48

45
6.0

45.8

15.7

7.4

10.1

4.2

8.7

8.1

Social network site use habits. There was an interest in learning about respondents' use habits and how they may vary between the popular and niche social network sites. To that end, the instrument asked questions to gather data about both the respondents Ravelry and Facebook use habits (i.e. log in frequency; communication activities; number of friends, etc.).

Patterns of Ravelry use. Participants were asked to report some general information about their Ravelry membership. Overall, the majority of respondents reported being Ravelry members for between 1 and 5 years. More specifically, 5.8\% ( $n=$ 32) of the respondents reported being members for less than 1 year; $56.5 \%(n=313)$ reported 1 - 5 years; and, 37.7\% $(n=209)$ said more than 5 years. Additionally, respondents reported on the number of friends they have on the site. More than $65 \%(n=$ 363) of respondents reported having 50 or fewer friends in Ravelry with an additional 9.4\% $(n=52)$ reporting zero friends. Of the remaining respondents, $12.1 \%(n=67)$ reported having between 51 and 100 friends; 8.5\% $(n=47)$ reported having between 101 and 200 friends; 3.1\% $(n=17)$ reported having between 201 and 500; and, 1.4\% $(n=8)$ reported having more than 500 Ravelry friends.

Respondents were also asked about some specific activities they may have participated in on Ravelry during the 60 days prior to taking the survey (1 - never, 2 - 
Less than once a month, 3 - once a month, 4 - two to three times per month, 5 - once a week, 6 - two to three times per week, 7 - daily; 8 - more than once a day). Respondents were asked how often they logged in to Ravelry $(M=7.14, S D=1.04)$. More than $77 \%$ of respondents reported logging in to the site at least once a day, including 252 of total respondents indicating that they log in more than once a day. Additionally, respondents reported that during the 60-day period in question they infrequently $(M=3.23, S D=$ 1.82) updated their Ravelry profiles including taking actions such as changing the information in their personal about me and notebooks. For example, 44.9\% $(n=249)$ indicated they made changes less often than once a month, where $2.9 \%(n=16)$ reported making these changes every day. Further, when asked how often they communicated with others on Ravelry $(M=4.89, S D=2.01), 38.8 \%(n=175)$ reported they had communicated with others on the site between once and three times per week. These activities included sending private messages, responding to forum posts, and commenting on posted projects and photos.

Patterns of Facebook use. Participants were also asked to report some general information about their Facebook membership in the same manner as they were regarding Ravelry. Overall, 49.5\% of respondents $(n=274)$ reported being Facebook members for more than 5 years. Additionally, 19 respondents (3.4\%) reported being members for less than 1 year; 261 respondents (47.1\%) reported being members between 1 and 5 years. When asked to report the number of Facebook friends they had, 7.7\% $(n=43)$ of respondents indicated having 10 or fewer friends and 4.5\% $(n=25)$ reported having more than 500 friends. Of the remaining respondents, 19.7\% ( $n=109)$ reported having between 11 and 50 friends; 21.7\% $(n=120)$ reported having between 51 and 100 friends; 26.7\% 
( $n=148)$ reported having between 101 and 200; and, 19.7\% $(n=109)$ reported having 201 to 500 Facebook friends.

Respondents were also asked to report some specific Facebook activities they may have participated in during the 60 days prior to taking the survey using the same measures for Ravelry activities (on a 1 to 8 scale; 1 = never, $8=$ more than once a day). Respondents were asked how often they logged in to Facebook $(M=6.32, S D=1.85)$. More than $69 \%$ of respondents $(n=365)$ reported logging in to the site at least once a day, including 141 of total respondents indicating that they log in more than once a day. Additionally, the majority of respondents $(n=375,67.7 \%)$ reported that during the 60 day period in question they updated their Facebook profiles less than once a month. A total of 59 respondents (10.7\%) indicated that they updated their profiles once a week or more.

When asked how often they communicated with others on Facebook $(M=5.16$, $S D=2.08), 304(54.9 \%)$ respondents reported communicating with others on Facebook at least 2 to 3 times per week. Of that group, 68 respondents indicated that they communicated with others on Facebook more than once each day. These activities included sending private messages, commenting on and liking their friends’ posts. Table 2 offers a complete listing of all use pattern data for both Ravelry and Facebook collected from respondents.

Table 2: Combined Patterns of Use $(N=554)$

\begin{tabular}{lcccc} 
& \multicolumn{2}{c}{ SNS = Ravelry } & \multicolumn{2}{c}{ SNS = Facebook } \\
\hline & Frequency & Percentage & Frequency & Percentage \\
\cline { 2 - 5 } How long have you been a [SNS] member? & $(M=2.32, S D=.58)$ & $(M=2.46, S D=.56)$ \\
Less than 1 year & 32 & 5.8 & 19 & 3.4 \\
1 - 5 Years & 313 & 56.5 & 261 & 47.1 \\
More than 5 years & 209 & 37.7 & 274 & 49.5 \\
In the last 60 days, how often have you logged into & $(M=7.14, S D=1.04)$ & $(M=6.32, S D=1.85)$
\end{tabular}




\begin{tabular}{|c|c|c|c|c|}
\hline \multicolumn{5}{|l|}{ [SNS]? } \\
\hline Never & 4 & 0.7 & 22 & 4.0 \\
\hline Less than one a month & 0 & 0.0 & 21 & 3.8 \\
\hline Once a Month & 1 & 0.2 & 16 & 2.6 \\
\hline 2-3 Times a Month & 5 & 0.9 & 27 & 4.9 \\
\hline Once a Week & 14 & 2.5 & 31 & 5.6 \\
\hline 2-3 Times a Week & 101 & 18.2 & 72 & 13.0 \\
\hline Daily & 177 & 31.9 & 224 & 25.5 \\
\hline More than Once a Day & 252 & 45.5 & 141 & 25.5 \\
\hline $\begin{array}{l}\text { In the last } 60 \text { days, how often have you updated your } \\
\text { [SNS] profile? }\end{array}$ & \multicolumn{2}{|c|}{$(M=3.23, S D=1.82)$} & \multicolumn{2}{|c|}{$(M=2.33, S D=1.49)$} \\
\hline Never & 118 & 21.3 & 201 & 36.3 \\
\hline Less than Once a Month & 131 & 23.6 & 174 & 31.4 \\
\hline Once a Month & 62 & 11.2 & 72 & 13.0 \\
\hline 2-3 Times a Month & 99 & 17.9 & 48 & 8.7 \\
\hline Once a Week & 60 & 10.8 & 27 & 4.9 \\
\hline 2-3 Times a Week & 68 & 12.3 & 26 & 4.7 \\
\hline Daily & 11 & 2.0 & 5 & 0.9 \\
\hline More than Once a Day & 5 & 0.9 & 1 & 0.2 \\
\hline $\begin{array}{l}\text { In the last } 60 \text { days, how many times have you } \\
\text { communicated with others on [SNS]? }\end{array}$ & \multicolumn{2}{|c|}{$(M=4.89, S D=2.01)$} & \multicolumn{2}{|c|}{$(M=5.16, S D=2.08)$} \\
\hline Never & 38 & 6.9 & 47 & 8.5 \\
\hline Less than Once a Month & 53 & 9.6 & 36 & 6.5 \\
\hline Once a Month & 39 & 7 & 38 & 6.9 \\
\hline 2-3 Times a Month & 96 & 17.3 & 65 & 11.7 \\
\hline Once a Week & 79 & 14.3 & 64 & 11.6 \\
\hline 2-3 Times a Week & 136 & 24.5 & 148 & 26.7 \\
\hline Daily & 52 & 9.4 & 88 & 15.9 \\
\hline More than Once a Day & 61 & 11 & 68 & 12.3 \\
\hline How Many friends do you have in [SNS]? & \multicolumn{2}{|c|}{$(M=2.94, S D=1.29)$} & \multicolumn{2}{|c|}{$(M=4.41, S D=1.41)$} \\
\hline 0 & 52 & 9.4 & 19 & 3.4 \\
\hline $1-10$ & 174 & 31.4 & 24 & 4.3 \\
\hline $11-50$ & 189 & 34.1 & 109 & 19.7 \\
\hline $51-100$ & 67 & 12.1 & 120 & 21.7 \\
\hline $101-200$ & 47 & 8.5 & 148 & 26.7 \\
\hline $201-500$ & 17 & 3.1 & 109 & 19.7 \\
\hline More than 500 & 8 & 1.4 & 25 & 4.5 \\
\hline
\end{tabular}

Use frequency. Additionally, based on the nature of the particular niche that Ravelry caters to, this study was interested in seeing how users would characterize the frequency of their own use and in getting a sense of the degree to which use of the site and use of Facebook might be influenced by the time of the year. 
Ravelry use frequency. When asked to characterize the frequency of their Ravelry use $(M=1.26, S D=.52)$, the majority $(n=428,77.3 \%)$ indicated that they were daily users of the site. One-hundred ten (19.9\%) respondents characterized their use as weekly; $13(2.3 \%)$ respondents characterized their use as monthly; and $3(0.5 \%)$ indicated they were only occasional users. When asked if there were times of the year when they are more likely to use Ravelry, 435 respondents indicated that their use is likely to be the same all the time. Seventy-seven respondents indicated that they were more likely to use Ravelry when preparing for special occasions or during the holidays. The remaining 42 respondents indicated that there are likely to use the site sporadically.

When asked whether time of the year influenced the frequency of their Ravelry use, 442 respondents indicated that they are likely to use Ravelry with the same frequency year-round. One-hundred twelve respondents, however, reported that they experience seasonal change in their use of the site: 62 respondents were more likely to use the site in the winter; 8 were more likely to use the site in the spring; 7 were more likely to use the site during the summer; and, 35 were more likely to use the site in the fall.

Facebook use frequency. When asked about the frequency of their Facebook use $(M=1.61, \mathrm{SD}=.99)$, the majority $(n=362,65.3 \%)$ characterized their use of the site as daily. One-hundred seven (19.3\%) respondents characterized their use as weekly; 26 (4.7\%) respondents characterized their use as monthly; and 59 (10.6\%) indicated they were only occasional users. Three-hundred thirty-four respondents indicated that they were likely to use Facebook the same all the time. When asked if there were times of the year when they are more likely to use Facebook, 42 respondents indicated that they were 
more likely to use the site when preparing for special occasions or during the holidays and 178 respondents indicated that they are likely to use Facebook sporadically.

When asked whether time of the year influenced the frequency of their Facebook use, 535 respondents indicated that the seasons have no influence and they are likely to use Facebook with the same frequency year-round. Only 19 respondents reported that they experience seasonal changes in their use of Facebook: 11 respondents were more likely to use the site in the winter; 1 was more likely to use the site in the spring; 4 were more likely to use the site during the summer; and, 3 were more likely to use the site in the fall.

Table 3 displays a side-by-side comparison of the data collected from respondents on how they would characterize the frequency of their Ravelry and Facebook use.

Table 3: Combined SNS Use Characterization $(N=554)$

\begin{tabular}{|c|c|c|c|c|}
\hline & \multicolumn{2}{|c|}{ SNS = Ravelry } & \multicolumn{2}{|c|}{ SNS = Facebook } \\
\hline & Frequency & Percentage & Frequency & $\begin{array}{c}\text { Percentag } \\
\mathrm{e}\end{array}$ \\
\hline $\begin{array}{l}\text { How would you Characterize how frequently you use } \\
\text { (SNS) throughout the year? }\end{array}$ & \multicolumn{2}{|c|}{$(M=1.26, S D=.523)$} & \multicolumn{2}{|c|}{$(M=1.61, S D=.987)$} \\
\hline Daily & 428 & 77.3 & 362 & 65.3 \\
\hline Weekly & 110 & 19.9 & 107 & 19.3 \\
\hline Monthly & 13 & 2.3 & 26 & 4.7 \\
\hline Occasionally (less than monthly) & 3 & 0.5 & 59 & 10.6 \\
\hline \multicolumn{5}{|l|}{ I am likely to use (SNS). } \\
\hline The same all the time. & 435 & 78.5 & 334 & 60.3 \\
\hline More around the holidays. & 34 & 6.1 & 9 & 1.6 \\
\hline More when planning for special occasions. & 43 & 7.8 & 33 & 6.0 \\
\hline Sporadically. & 42 & 7.6 & 178 & 32.1 \\
\hline \multicolumn{5}{|l|}{ I use (SNS)... } \\
\hline The same year-round. & 442 & 79.8 & 535 & 96.6 \\
\hline More in the winter & 62 & 11.2 & 11 & 2.0 \\
\hline More in the spring & 8 & 1.4 & 1 & $<1$ \\
\hline More in the summer & 7 & 1.3 & 4 & $<1$ \\
\hline More in the fall. & 35 & 6.3 & 3 & $<1$ \\
\hline
\end{tabular}




\section{Results}

\section{Social Network Site Use Motives}

Ravelry Use Motives. Research question one (RQ1) asked, "What are the motives for niche social network site use?” In addressing this question, respondents were asked to indicate how much they agree with a series of items about why they use the niche SNS Ravelry. Respondent answers were measured on a 5-point Likert scale (1 = strongly disagree, 5 = strongly agree). Principal components analysis with Varimax rotation was used to extract and interpret possible Ravelry use motive factors from these items adapted based on Papacharissi and Mendelson’s (2011) scale for measuring motives for Facebook use (see Appendix $C$ ). A total of eight factors with eigenvalues greater than $+/-1.0$ emerged.

In determining whether to retain these factors, the 60/40 criteria outlined by Stack (2011) were used. Stacks explains that, “'good’ factors are produced by (1) at least two items that 'load' at +/- .60 and (2) do not 'load' on other factors greater than $+/-.40$, thus producing a clean dimension” (p. 59). From the Ravelry use motives scale, 1 factor and 11 total items did not adhere to Stacks' (2011) criteria and were dropped from further analysis.

Finally, Field (2013) recommended that if several factors exist, reliability of the items making up each factor should be measured separately as a subscale. The reliability

of items contributing to each retained factor was measured using coefficient alpha. Acceptable reliability coefficients are those .70 or higher, with coefficients of .90 or 
higher considered “excellent” (Stacks, p. 51, 2011). The seven remaining factors all had acceptable reliability coefficients and were retained for further analysis.

Table 4 summarizes the seven retained Ravelry uses motive factors and individual item loadings.

Table 4: Summary of Ravelry Use Motive Factors and Items

\begin{tabular}{|c|c|c|c|}
\hline Factors and Items & Loadings & $\alpha$ & Variance Explained \\
\hline Factor 1: Relaxing entertainment & & .828 & $26.76 \%$ \\
\hline Because it relaxes me. & .736 & & \\
\hline Because it allows me to unwind. & .724 & & \\
\hline Because it is fun. & .710 & & \\
\hline To entertain myself. & .687 & & \\
\hline Because it is enjoyable entertainment. & .675 & & \\
\hline Factor 2: Habitual pass time & & .821 & $11.41 \%$ \\
\hline Because it passes the time away. & .767 & & \\
\hline To give me something to do to occupy my time. & .735 & & \\
\hline Out of habit. & .724 & & \\
\hline To help pass the time when I am bored. & .722 & & \\
\hline Factor 3: Social interaction & & .878 & $6.99 \%$ \\
\hline To keep in touch with friends or family. & .822 & & \\
\hline To communicate with distant friends. & .819 & & \\
\hline For chatting with people I otherwise would lose contact with. & .804 & & \\
\hline Factor 4: Expressive information sharing & & .792 & $4.46 \%$ \\
\hline To share my knowledge and expertise. & .752 & & \\
\hline To share my views. & .749 & & \\
\hline To share information that may be of interested or useful to others. & .724 & & \\
\hline To tell others about my opinions. & .689 & & \\
\hline Factor 5: New friendships & & .719 & $3.49 \%$ \\
\hline To communicate with like-minded people. & .686 & & \\
\hline Find groups of people who share my interests. & .680 & & \\
\hline To feel like I am a part of a group. & .607 & & \\
\hline Factor 6: Professional advancement & & .808 & $3.18 \%$ \\
\hline Because it is helpful for my career. & .833 & & \\
\hline To sell my patterns or products. & .793 & & \\
\hline To help me network with professional contacts. & .767 & & \\
\hline Factor 7: Cool new technology & & .711 & $2.82 \%$ \\
\hline Because it's the thing to do. & .800 & & \\
\hline
\end{tabular}


Note. All items included the opening "I use Ravelry..."

The factor analysis of Ravelry use motive statements yielded seven interpretable factors, or motives for using Ravelry, that accounted for $59.12 \%$ of the variance: relaxing entertainment $(M=4.04, S D=0.64)$, habitual pass time $(M=3.14, S D=0.94)$, social interaction $(M=2.50, S D=1.12)$, expressive information sharing $(M=3.25, S D=0.79)$, new friendships $(M=3.88, S D=0.79)$ professional advancement $(M=1.91, S D=0.89)$, and cool new technology $(M=2.37, S D=0.84)$.

Responses to all the retained items were summed and averaged to form the subscales representing each factor. These scores formed new variables that were used for the additional analysis.

Facebook Use Motives. Research question two (RQ2) asked, “What are the motives for popular social network site use?” In addressing this question, responses within the data collected from respondents on their motives for using Facebook were analyzed. The same set of criteria were used to extract and interpret possible Facebook use motive factors as those criteria used in extracting the Ravelry use motive factors. A total of eight factors with eigenvalues greater than +/- 1.0 emerged through the principal components analysis with Varimax rotation.

Factors with at least two items loading at $+/-.60$ or greater that did not load on other factors at greater than +/- .40 were retained for future evaluation (Stacks, 2011). Two factors and 15 items from the Facebook use motives scale were dropped from further analysis by applying these criteria. The remaining six Facebook use motive 
factors were subjected to reliability analysis and were retained after demonstrating a coefficient alpha greater than .70 .

Table 5 summarizes the six retained Facebook Uses Motive factors and individual item loadings.

Table 5: Summary of Facebook Use Motive Factors and Items

\begin{tabular}{|c|c|c|c|}
\hline Factors and Items & Loadings & $\alpha$ & Variance Explained \\
\hline Factor 1: Habitual pass time & & .926 & $42.35 \%$ \\
\hline To give me something to do to occupy my time. & .802 & & \\
\hline To help pass the time when I am bored. & .796 & & \\
\hline Because it passes the time away. & .776 & & \\
\hline Out of habit. & .744 & & \\
\hline Because it is just something I do. & .711 & & \\
\hline So I can get away from what I am doing. & .616 & & \\
\hline Factor 2: Relaxing entertainment & & .903 & $7.97 \%$ \\
\hline Because it relaxes me. & .718 & & \\
\hline Because it is fun. & .700 & & \\
\hline Because it helps me relax after school or work. & .681 & & \\
\hline Because it is enjoyable entertainment. & .659 & & \\
\hline Factor 3: Expressive information sharing & & .847 & $6.03 \%$ \\
\hline To share my views. & .813 & & \\
\hline To tell others about my opinions. & .775 & & \\
\hline $\begin{array}{l}\text { To share information that may be of interested or useful to } \\
\text { others. }\end{array}$ & .677 & & \\
\hline Factor 4: Professional advancement & & .831 & $3.63 \%$ \\
\hline Because it is helpful for my career. & .877 & & \\
\hline To help me network with professional contacts. & .821 & & \\
\hline To post my resume and/or other work online. & .769 & & \\
\hline Factor 5: Social interaction & & .862 & $3.08 \%$ \\
\hline To communicate with distant friends. & .854 & & \\
\hline For chatting with people I otherwise would lose contact with. & .813 & & \\
\hline To keep in touch with friends or family. & .807 & & \\
\hline Factor 6: 2 Cool new technology & & .774 & $2.50 \%$ \\
\hline Because everyone else is doing it. & .789 & & \\
\hline Because it's the thing to do. & .754 & & \\
\hline
\end{tabular}

Factor analysis produced six interpretable Facebook use motive factors accounting for $65.57 \%$ of the variance: habitual pass time $(M=2.81, S D=1.04)$, 
relaxing entertainment $(M=2.75, S D=1.01)$, expressive information sharing $(M=2.69$, $S D=1.04)$, professional advancement $(M=1.87, S D=0.87)$, social interaction $(M=$ 4.09, $S D=0.93)$, and cool new technology $(M=2.46, S D=1.04)$.

Responses to all of the retained items from the Facebook use motive factors were summed and averaged to form the subscales representing each factor.

A complete list of all deleted items from both the Ravelry use motive scale and Facebook use motive scale is located at Appendix E.

\section{Social Network Site Motives Compared}

Research question three (RQ3) asked: “How do motives for using niche social network sites compare with motives for using a popular social network site?” In addressing this question, it was necessary to consider the use motives that emerged during the factor analysis for each SNS; the items that loaded to each factor that emerged; and, the importance given to each use motive by the respondents.

Both the Ravelry use motive scale $(\mathrm{a}=.959)$ and Facebook use motive scales $(\mathrm{a}=$ .916) contained items adapted from Papacharissi and Mendelson (2011) and were intended to measure 12 use motive categories: pass time, relaxation, entertainment, information sharing, professional advancement, companionship, social interaction, cool and new technology, self-expression, habit, escape, and new friendships.

There was a considerable amount of overlap between the factors that emerged from the Ravelry use motive scale and those that emerged from the Facebook use motive scale. Two factors emerged from the factor analysis of both scales that represent the a priori categories as they were originally conceptualized. Professional advancement emerged as a motive for use of both Ravelry ( $\alpha=.808$, variance explained $=3.18 \%$ ) and 
Facebook $(\alpha=.831$, variance explained $=3.63 \%)$ and contained only the three respective items representing the category as it was conceptualized by Papacharissi and Mendelson (2011). Additionally, social interaction also emerged as a use motive for both Ravelry ( $\alpha$ $=.878$, variance explained $=6.99 \%)$ and Facebook $(\alpha=.862$, variance explained $=$ 3.08\%) and was also a clean representation of the way the a priori category was conceptualized.

In addition to the two factors that emerged as clean concepts, overlap also existed in other factors that varied slightly in the way the items loaded from one SNS to the other. The factor cool new technology emerged from both scales however, the item "because it is cool" only loaded on the Ravelry factor $(\alpha=.711$, variance explained $=$ 2.82\%). The fact that the items, "because everyone else is doing it" and "because it is the thing to do" still loaded on Facebook factor $(\alpha=.744$, variance explained $=2.50 \%)$ indicates that there is a social expectation to be on Facebook even if the coolness or newness does not influence users’ motives as it appears to with Ravelry use.

The factor of relaxing entertainment also emerged as a motive for using both social network sites with the item loadings varying between the sites. The Ravelry factor $(\alpha=.828$, variance explained $=26.76 \%)$ combined the two items from the a priori category relax and three from entertainment. The Facebook factor ( $\alpha=.903$, variance explained $=7.97 \%$ ), on the other hand, combined two items from the a priori category relax and two from entertainment. Both combinations indicate that use is motivated by a passive approach to seeking entertainment through the SNSs.

Habitual pass time also emerged as a factor for both SNSs with varied item loadings. The three items from the a priori category pass time loaded to both factors. As a 
motive for using Ravelry ( $\alpha=.821$, variance explained $=11.41 \%$ ), the factor also included one item from the habit category. As a motive for using Facebook $(\alpha=.926$, variance explained $=42.35 \%$ ), the factor included two items from the category habit and a single item from the category escape. The addition of the element of escape in the Facebook factor implies that this motive for using Facebook has an element of procrastination to the habitual use of the SNS to pass time.

The motive of expressive information sharing emerged as both a Ravelry factor ( $\alpha$ $=.792$, variance explained $=4.46 \%)$ and a Facebook factor $(\alpha=.847$, variance explained $=6.03 \%)$. As a Ravelry use motive, the factor combined two items from the category self-expression and two from the category information sharing. As a motive for using Facebook, the factor had only three items load, two from self-expression and one from information sharing. Both sets of loadings indicate that SNS use is motivated by a need to share both general and personal information. However, the specific items that loaded to both the Ravelry and Facebook factors indicate that this motive weighs slightly more toward the need to share personal information.

The most significant difference between the factors that emerged from the two use motive scales was a single factor that emerged only from the factor analysis of one scale. The factor of new friendships ( $\alpha=.719$, variance explained $=3.49 \%$ ) emerged only from the Ravelry use motive scale. One item from the category companionship and two original items added by the present study to the a priori category of new friendships loaded to this motive. The factor was comprised of the items, “To communicate with like-minded people”; “Find groups of people who share my interests”, and "To feel like I am a part of a group.” Based on these loadings, this factor indicates that Ravelry use is 
motivated by a need to join groups and find new connections that is not seen in Facebook use.

Items from the a priori category escape did not load to any emerging Ravelry factor. Items from the a priori categories of new friendships and companionship did not load to any of the Facebook factors that emerged.

This comparison of the results of the factor analyses and the motives that emerged from both the Ravelry use motive and Facebook use motive scales suggests that underlying similarities do exists between the motives for using niche SNSs and the motives for using popular SNSs. However, the emergence of the new friendships motive for using Ravelry is most significant.

A complete summary of Ravelry use motives is located in Table 4 and the summary of Facebook use motives is located in Table 5.

In examining the results, a focus on the relevance of the mean scores for each use motive subscale demonstrated in a little more detail some differences that exist between Ravelry use motives when compared to Facebook use motives.

Ravelry relaxing entertainment $(M=4.04, S D=0.64)$ and Ravelry new friendships $(M=3.88, S D=0.79)$ had the highest mean scores of the Ravelry use motives, indicating that these motives were more likely to be salient to most of the respondents. In contrast, Facebook social interaction $(M=4.09, S D=0.93)$ had the highest mean score, rendering it the most salient Facebook use motive to the study's sample. This indicates that most respondents seek to use Ravelry for its role in relaxation and to foster new friendships and are most likely to use Facebook to maintain existing relationships with friends and family. The motives of professional advancement and cool 
new technology were the least salient on both the Ravelry use motive and Facebook use motive scales. The mean scores for Ravelry cool new technology $(M=2.37, S D=0.84)$, Ravelry professional advancement $(M=1.91, S D=0.89)$, Facebook cool new technology $(M=2.46, S D=1.04)$, and Facebook professional advancement $(M=1.87, S D=0.87)$ indicate that these were more likely to be significant for a very specific and smaller part of the study population.

From the Ravelry use motives, expressive information sharing $(M=3.25, S D=$ $0.79)$ and habitual pass time $(M=3.14, S D=0.94)$ were also fairly important factors. To a lesser extent, Ravelry social interaction $(M=2.50, S D=1.12)$, Facebook habitual pass time $(M=2.81, S D=1.04)$, Facebook relaxing entertainment $(M=2.75, S D=.1 .00)$, and Facebook expressive information sharing $(M=2.69, S D=1.04)$ were likely salient to a smaller portion of the sample.

Table 6 summarizes the subscale means and standard deviations.

\begin{tabular}{lll} 
Table 6: Summary of Subscale Means \& Standard deviations & \\
Ravelry Factor & M & \\
\hline Relaxing Entertainment & 4.04 & 0.64 \\
New Friendships & 3.88 & 0.79 \\
expressive information sharing & 3.25 & 0.79 \\
Habitual Pass Time & 3.14 & 0.94 \\
Social Interaction & 2.50 & 1.12 \\
Cool New Technology & 2.37 & 0.84 \\
Professional Advancement & 1.91 & 0.89 \\
Facebook Factor & & \\
\hline Social Interaction & 4.09 & 0.93 \\
Habitual Pass Time & 2.81 & 1.04 \\
Relaxing Entertainment & 2.75 & 1.00 \\
expressive information sharing & 2.69 & 1.04 \\
Cool New Technology & 2.46 & 1.04 \\
Professional Advancement & 1.87 & 0.87
\end{tabular}

Note. Factors arranged in descending order by mean. 


\section{Open-ended Reponses}

As part of gathering the data needed to gauge motives for using SNSs, the survey instrument included six open-ended questions in order to inform the results of the study and ensure that any motives unique to the selected niche and popular SNS were not overlooked.

Facebook. In the case of the Facebook use motives, the responses received through the open-ended questions supported the findings. Through the factor analysis, Facebook use motives emerged as social interaction, habitual pass time, relaxing entertainment, expressive information sharing, cool new technology, and professional advancement. Social interaction was by far the most salient motive to the most respondents with a $M$ of 4.09 and $S D$ of .93 . Social interaction was followed by the Facebook use motive habitual pass time proving less salient to a smaller portion of the sample with its $M$ of 2.81 and $S D$ of 1.04. In reviewing the responses to open-ended questions on Facebook use, the strong salience of social interaction was also clearly reflected. In response to the question, “why did you join Facebook?,” 49\% of respondents indicated that they sought memberships to stay in touch with friends or family. For example, one respondent said, “To find people I'd lost touch with [and] post family pictures for distant family members.”

An additional 15\% indicated that they were asked or felt pressured to join by friends or family that wished to stay in touch. One respondent said, "My family made me do it," and another added, "because family members stopped updating anywhere else.” 
An unexpected subcategory of the social interaction motive that emerged from the open-ended responses is that $5 \%$ of respondents stated that they had joined Facebook to supervise their family member use of the site:

“To keep track of my teenage children.”

“To supervise my children's activities.”

"My mother joined it when I was 17. I didn't have a Facebook, and I had to have a method of damage control as to what she put up about me--so I joined.”

The next largest motive indicated by respondents for joining Facebook was that it was a cool new technology with $23 \%$ stating things like, they joined, "to see what all the fuss was about,” or "I had read about it somewhere and wanted to see what it was all about.” The remaining motives for joining Facebook represented in the open-ended responses included joining for entertainment, general interest, information sharing and professional advancement but made up only $8 \%$ of responses when combined.

Respondents were also asked to describe in their own words why they use Facebook. These responses also supported the findings of the factor analysis with $83 \%$ of respondents indicating that their primary motive for using the site is social interaction with existing friends and family members. Additional uses previously identified through the factor analysis included relaxing entertainment, habitual pass time, expressive information sharing, and professional advancement and, when combined, accounted for $16 \%$ of responses.

Two motives for using Facebook not seen in through the factor analysis emerged from these responses. Meeting new people and shopping were listed as primary motives for using Facebook however, are considered insignificant as they accounted for $1 \%$ of responses. 
Though the structure of the question did not lend itself strictly to revealing motives for using the site, respondents were also asked, "why do you find Facebook appealing?” More than 33\% of respondents indicated that the site is appealing because it allows them to facilitate social interactions with existing friends and family members. This further supports the findings of the factor analysis. Respondents also indicated that the site is appealing because it is easy of use, entertaining, a source of news and information, helps pass time, facilitates professional advancement, and because of its popularity and large population.

The question of why respondents find Facebook appealing made the false assumption that all of the site's users find it appealing. Unexpectedly, 35\% of respondents indicated that they do not. Disagreement with the site’s appeal varied between respondents. Many simply stated that, "I don’t.” Others expressed varying degrees of dislike for Facebook from, “I don’t. It’s a necessary evil” to “I think Facebook is the devil" and "I find it utterly appalling."

Ravelry. The data from the factor analysis of the Ravelry use motive scale revealed that relaxing entertainment, new friendships, expressive information sharing, habitual pass time, social interaction, cool new technology, and professional advancement were all motives for use of the site Ravelry. In part, the responses provided by respondents in the open-ended questions supported the findings of the factor analysis. One of the most salient motives emerging from the Ravelry use motive scale was new friendships with a $M$ of 3.88 and $S D$ of .79 . When asked to describe in their own words why they use Ravelry, 25\% of the responses indicated that their primary motive for use included some aspect of the new friendships motive. For example, one respondent said, "I 
did not realize that it would open up a whole new world to me, introducing me to people who enjoyed knitting as much as I do.”

Additionally, when asked, "Why did you join Ravelry?,” 11\% of the responses indicated that new friendships (i.e. connecting with strangers, meeting new people, etc.) was a primary motive in the decision to seek site membership. An example respondent said, “[I] didn't have any knitting groups in my area and wanted to read about knitting, spinning, weaving and talk with people who share my interest.”

As added support, the new friendships motive was the most often cited with $26 \%$ of responses indicating it was Ravelry’s primary appeal.

In addition to confirming new friendships as a salient motive for using Ravelry, some of the open-ended responses identified other existing motives that emerged through the factor analysis of the Ravelry use motive scale. When asked why they joined Ravelry, one other of the previously identified motives was supported by the open-ended responses. Twelve percent of respondents reported that cool new technology was their primary motive for joining the site.

When asked to describe in their own words why they use Ravelry, less than $6 \%$ of the remaining responses showed previously identified motives as their primary motive for use of Ravelry: habitual pass time, relaxing entertainment, professional advancement and expressive information sharing.

Finally, Relaxing entertainment and expressive information sharing were also identified by less than $1 \%$ of open-ended responses to the question of Ravelry's appeal.

On the other hand, many of the responses to the open-ended questions indicate that the a priori categories that were measured by the instrument did not fully capture the 
motives for joining or continuing to use Ravelry. For example, 58\% of the responses to the open-ended question of why they joined indicated that the primary motives were resources available within the site ranging from tools (i.e. databases, search functions, organization capabilities) and information to education. Additionally, 20\% indicated they joined based solely on recommendations from others and 9\% said they joined because of general interest in the site. Of those respondents that indicated that their motive for joining the site was tools and resources, 195 respondents specifically cited the availability of knitting patterns. One respondent said, “originally for the patterns,” and another, “initially for the patterns and yarn ideas,” and another, "patterns, patterns, patterns.” Motives also emerged that were not seen in the Ravelry use motive scale when respondents were asked to describe in their own words why they use the site. The most significant motives that emerged out of this question were tools and access to information. Thirty-eight percent of respondents indicated that using tools within the site was their primary use motive:

"Because of the awesome pattern and yarn databases."

“To keep track of projects I am working on, have worked on, and want to work on."

"Being able to view peoples finished projects and read any notes they may have made, so useful prior to buying wool and starting a project."

Again, 92 respondents specifically called out the access to patterns as a primary motive for continuing to use Ravelry.

Access to information was the second most significant motive identified by respondents when asked to describe why they use Ravelry. Nineteen percent of responses indicated that information was their primary motive for use. Exemplary responses 
included: "I like having access to all the craft-related information"; "It's the best comprehensive source for knitting information"; and, "valuable wealth of information in one spot.”

Though less significant, other motives that emerged from respondents descriptions of their reasons for using Ravelry that were not previously identify through the factor analysis included: education (9\%); access to expert advice (.5\%); source of inspiration (2\%); and, shopping (.5\%).

When respondents were asked why they find Ravelry appealing, only three additional appeals emerged that had not been previously identified through the factor analysis or through the other open-ended questions. Four respondents indicated that they find Ravelry appealing because it is affordable (i.e. membership is free); 25 indicated the appeal of the exclusive, focused content; and, 53 indicated that Ravelry is appealing because it is easy to use.

No respondents indicated that they did not find Ravelry appealing as seen in their responses to Facebook. 


\section{Discussion}

\section{Limitations}

As seen in the results, the motive scale selected for measure was a valuable tool in identifying the features, functions, and content available within a social network site as a product of identifying the motives for use. The motive scale selected to collect data in the present study produced valuable information but presented a limitation. Future research that attempts to understand the motivations of the niche SNS audience should consider creating a new scale or adapting a more comprehensive existing scale to measure motives for use of these sites. While the instrument developed by Papacharissi \& Mendelson (2011) measured 11 use motive categories representing a combination of interpersonal, media, newer media, and professional advancement motives, it was unable to detect use motives unique to the niche SNS. An overarching scale intended to test for motives of Internet use as a whole, for example, would be more apt to draw out uses specific to a distinct classification of SNS. In addition, a more comprehensive scale would allow future research to compare other popular SNSs, such as Twitter or Pinterest, with niche SNSs or compare multiple niche SNSs.

Future research on any SNS, popular or otherwise, should also consider scale items that draw a distinction between relationships with friends and relationships with family. The heavy focus of past research on the use of Facebook has led to a blending of these groups based on the nature of one particular SNS.

The non-probability sampling method used was another limitation of the present study. Although the sample size was acceptable, there was no way to ensure it was 
representative of the Ravelry population. This was one of the elements that may have prevented the study from drawing a demographically-diverse sample. The niche SNS selected for this exploratory research also hindered the sample. The study was disproportionately female, likely as a result of the particular niche catered to on Ravelry. The resulting sample was only $2.2 \%$ males. The inverse may have been true had the site selected catered to a predominately-male niche pastime.

Distributing the survey and recruiting participants through the niche social network site added a limitation to the study that should be acknowledged. This strategy likely contributed to some of the negativity toward Facebook reflected in the open-ended responses. However, this approach was deemed unavoidable in order to gain an adequate sample size consisting of respondents who were both Ravelry and Facebook members. When the survey launched, the Ravelry and Facebook populations were roughly 3.4 million and 1.2 billion respectively. The probability of recruiting a Ravelry member who was also a member of Facebook was far greater than that of recruiting a Facebook member who was also a Ravelry member. The likelihood of not reaching an adequate sample size would have increased exponentially had this study attempted to recruit participants from the Facebook population.

As with any method of data collection, survey research has its limitations. With surveys, the reliability of self-reported data is difficult to measure. A well-known criticism of uses and gratifications approaches is the inability to confirm the veracity of the respondents' answers (Ruggeiro, 2000). The nature of the Internet adds some challenges to sampling. While other researchers have noted that capturing a random sample can prove difficult (Kaye and Johnson, 2002), the primary disadvantage to data 
collection via the Internet is that there is no method to tell whether the person who completed the study was the intended recipient (Wimmer \& Dominick, 2011).

\section{Implications and Future Research}

Aimed at understanding niche social network sites and their users, the purpose of this study was to determine how audience motives for using niche social network sites compared with motives for using popular social network sites. The approach to making this comparison was adopted from the approach developed by Papacharissi and Mendelson’s (2011) study on Facebook uses.

The present study had four primary findings. First, the results demonstrated that there was a significant amount of overlap between the motives for using Ravelry and those for using Facebook. Second, the most salient motives for using Ravelry and Facebook differ. Third, unlike the findings in much of the existing research on Facebook and popular SNSs, Ravelry users are more likely to seek the development of new friendships through their niche SNS use. Fourth, the study identified personal utility and information seeking motives for use of Ravelry not seen in past studies of social network sites.

In terms of overlapping results, the motives of relaxing entertainment, expressive information sharing, habitual pass time, social interaction, cool new technology and professional advancement all emerged during the separate factor analyses of both the Ravelry use motive and Facebook use motive scales. The strength of the salience varied between the sites but all were represented.

The results showed that the most prominent motives for using each site differed. Not surprising, the most significant motive for using Facebook emerged as social 
interaction. The motive encompassed the items "to keep in touch with friends or family"; "to communicate with distant friends"; and, "for chatting with people I otherwise would lose contact with,” and indicates that the strongest motive for using Facebook in this study was related to maintaining existing relationships. As seen in the literature review, past studies have demonstrated that sites like Facebook are used to maintain or extend existing offline relationships (e.g. Choi, 2006; Ellison et al., 2007; Lampe et al., 2006; Sheldon, 2008). The results of the present study support the past findings and demonstrate that Facebook remains a means for users to maintain existing relationships.

In contrast, the most salient motives for using Ravelry that emerged through the factor analysis proved to be relaxing entertainment and new friendships--an obvious difference from the Facebook top motive. This accentuates a significant difference between the motives for using the niche SNS and the popular SNS and runs counter to the aforementioned results on relationship maintenance in SNSs.

Only one motive emerged through the factor analysis that was not applicable to both SNS use scales: new friendships. This distinct motive emerged only from the analysis of the Ravelry use motive scale. This clearly illustrates the finding that users were more likely to seek the development of new relationships on Ravelry than on Facebook. The significance is only amplified by the finding that new friendships was one of Ravelry's most prominent use motives.

An additional difference between the motives for using Ravelry and those for using Facebook is seen in the way the factor of cool new technology emerged from the use motive scales for each site. The item "because it is cool" only loaded to the Ravelry factor. The items "because everyone else is doing it" and "because it is the thing to do" 
still loaded on the Facebook factor and reflects the existence of a social expectation or pressure to be on Facebook.

The existence of social pressure to participate in Facebook was confirmed further by the results of the open-ended questions. Fifteen percent of respondents said that they were asked or felt direct pressure to join the site. Additionally, 35\% of respondents indicated that they do not like Facebook and do not find it appealing... yet, all of the respondents are Facebook members. This, combined with $83 \%$ percent of respondents stating that their primary motive for using the site was maintaining existing relationships, further supports the notion that there is a perceived pressure to participate in Facebook. One can theorize that these findings would likely not be seen in other popular social network sites (i.e. Twitter, Pinterest, etc.) where users are seeking information exchanges outside of connections with existing friends and family.

The fourth and most significant finding in the data collected was that $58 \%$ of the respondents indicated that their primary motives for joining Ravelry were resources available specific to the site, ranging from tools (i.e. databases, search functions, organization capabilities, etc.) and information to educational value and instruction. This finding tells us that niche SNS use is more instrumental and goal-oriented based on the utility of the functions within a particular niche site. Significant to any future study, this finding would have gone unidentified had the survey instrument not included the openended questions. This data provided the clearest view of variation between the two types of sites and demonstrated the existence of a real distinction between the motives for using the niche SNS when compared to the popular SNS, proving the thesis of this study and calling for a definition of niche social network site unto itself. 
The current definition of social network site may account for a narrowed view of motives that did not allow for the discovery of some of the Ravelry use motives. It was only though the open-ended responses that the present study discovered that the typology presented by Papacharissi and Mendelson (2011) is not necessarily applicable to every site that meets the standing definitions used to conceptualize social network sites. The a priori use categories measured though their scale did not capture motives unique to the niche SNS.

Papacharissi and Mendelson’s (2011) Facebook use motive scale was developed using a convergence of interpersonal, media, new media and professional development motives however, with the development of niche SNSs, proved insufficient. The findings of the present study suggest that niche SNS use motives include personal utility (organizing projects, tracking tools and yarn, etc.) and information seeking (product research, learning new techniques, expert advice, etc.) that were not present in the Facebook use motives identified by Papacharissi and Mendelson (2011).

This examination of niche SNSs began by using Boyd and Ellison's SNS definition as the lens for defining both the niche and popular SNS. This lens accounts for the degree of overlap discovered between the motives for using a niche SNS and a popular SNS. Both Ravelry and Facebook meet the requisite characteristics and are “...web-based services that allow individuals to (1) construct a public or semi-public profile within a bounded system, (2) articulate a list of other users with whom they share a connection, and (3) view and traverse their list of connections and those made by others within the system” (Boyd and Ellison, 2008, p. 211). 
Based on the findings, and the continued rapid growth of the social network site genre, Boyd \& Ellison's (2008) definition of social network site needs to be refined in a way that takes variations between SNSs into consideration. Beer (2008) was the first to identify that the current social network site definition is too broad, but did not offer a solution to narrow the field.

The way the concept of social network site is currently defined using the requisite characteristics set by Boyd and Ellison (2008) casts a very broad net that encompasses too many sites. For illustration, an apple can broadly be defined as a round fruit with a red, smooth, edible skin, and edible flesh. However, this definition can also be used to describe a cherry. Further saying that the fruit is cultivated from a tree in the rose family can still be too broad, again describing both an apple and a cherry. Through experience, we know that an apple and a cherry are inherently different. However, it isn’t until the following definitions are offered that we can see that their scientific classifications and seed composition are distinguishing characteristics:

Apple (n.): the fleshy usually rounded red, yellow, or green edible pome fruit of a usually cultivated tree (genus Malus) of the rose family. (“Apple,” n.d.)

Cherry (n.): a pale yellow to deep red or blackish smooth-skinned drupe [fruit] enclosing a smooth seed, from any of numerous trees and shrubs (genus Prunus) of the rose family. (“Cherry,” n.d.)

The findings of the present study demonstrate that popular and niche SNSs have distinguishing characteristics that warrant further exploration to refine their definitions. Each of the major findings identified motives for use that indicate these characteristics are found in the form of features, functions, or content specific to the individual sites actively selected by users. 
If we consider Boyd and Ellison's definition as the definition of social network site as an overarching category of web application, we can add to and expand this definition by identifying and developing a classification system to differentiate further between the sites that meet the current requisite for being called "social network site.” By continuing to rely on the broad definition, the potential for research to uncover differences that may be inherent to social network site sub-classifications will be lost. Further, by not clearly defining or identifying potential classifications among social network sites, we lose the ability to distinguish between the audiences, predict site use, and gauge the impact and potential effects of their use. The findings of the present study suggest that there are a number of possibilities to explore for creating social network site classifications.

The first distinction in classification between niche and popular social network sites that was originally proposed by the present study was to differentiate based on the target audience for membership. Popular social network sites are seen as being aimed at members of the general public, while niche SNSs are seen as having membership that is intended for individuals who share the common activity or interest catered to by the particular niche site.

By employing a uses and gratifications approach to compare the two sites, the present study was able to identify even clearer areas of distinction between them. The data gathered suggests additional classification possibilities among sites meeting the present definition of social network site based on identified use motives.

First, the findings show that the different types of information exchanges that motivate active selection of the niche and popular social network sites may aid in 
developing classifications among SNSs. The results of the two factor analyses indicate that members were motivated to use Facebook to exchange information (i.e. profile information, status updates, personal photos, etc.) as a means of relationship maintenance. Motives for using Ravelry, on the other hand, included information exchanges as a means of establishing relationships and for passive entertainment. Further, the results of the opened-ended questions show that motives for using Ravelry include information exchanges that support education and gaining resources that support execution of their chosen craft.

When determining the requisite characteristics that define social network sites, Boyd and Ellison (2008) actively "chose not to employ the term 'networking'” (p. 211). Networking by their account "emphasizes relationship initiation, often between strangers” and is not the primary practice on many SNS (Boyd \& Ellison, 2008, p. 211). These assertions may be exactly where future exploration should begin, as the results of the present study show that members were specifically seeking the use of niche SNSs with the goal of connecting with strangers.

Next, the uses and gratifications approach employed in the present study was instrumental in identifying motives for use of the niche SNS that offered perspective on functions, features, and content of interest to users that we would have not seen otherwise. The data gathered through the open-ended questions showed motives for use of the niche SNS that suggest an additional possibility for classification of SNSs. The findings tell us that niche SNS use is goal-oriented and can be based in the utility found on the site. Fifty-eight percent of respondents said that they joined Ravelry for these resources. Additionally, these site features--discovered as a product of identifying use 
motives--show us that the niche SNS not only allows users to create connections with people but also create connections between people and things (i.e. yarn, patterns, projects, etc.).

As discussed in the introduction, $U$ \& G theory assumes that (a) audience members are active and selective, (b) they are goal-oriented and aware of their needs, and (c) they select their particular type of media and content to satisfy those needs (Kaye \& Johnson, 2002; McQuail, 2000; Ruggiero, 2000). It stands to reason, then, that users are turning to Ravelry to satisfy specific needs that they perceive cannot be met through the information exchanges and features found in popular social network sites. 


\section{Conclusion}

With the wide variety of social network sites available for audiences, there is a clear need to differentiate among the ways audiences are using these sites. As is the case with Ravelry, audiences may be using these sites to meet new people and for the specialized functions offered only in one particular niche SNS. These motives for use differ from what research has learned by focusing heavily on Facebook use.

The uses and gratifications theory has repeatedly demonstrated its usefulness in understanding what draws audience members to new media and content. Using this approach here helped to identify variations in motives for using the popular verses the niche SNS and, by extension, allowed us to connect the identified motives with variations in the sites themselves.

The overarching purpose of this study was to understand how audiences are using social network sites. Past studies have examined the uses and gratifications sought in popular SNSs such as Facebook but until now research had not drawn a distinction between popular SNSs and those that cater to niche markets. This study not only added to the body of research aimed at understanding social network sites but, more specifically, it aided in identifying how uses and gratifications can be used to identify distinctions between classifications of SNS. As Ruggiero (2000) suggests, the design of U \& G studies assists in paring down a huge range of traits into manageable schema. This study assisted in the effort to refine a typology of motives audiences have for using these sites and in refining the way we think about social network sites. 
The findings of the present study demonstrated the need to refine the way the research community looks at social network sites and established the need to develop a system to further classify the hundreds of SNSs in use today. In doing so, the effort illustrated a clear need to explicate the definition currently being used to conceptually define social network(ing) sites. 


\section{Resources}

Acquisti, A., \& Gross, R. (2006). Imagined communities: Awareness, information sharing, and privacy on the Facebook. In P. Golle \& G. Danezis (Eds.), Proceedings of 6th Workshop on Privacy Enhancing Technologies (pp. 36-58). Cambridge, UK: Robinson College.

Apple. (n.d.). Merriam-Webster Dictionary online. Retrieved from http://www.merriamwebster.com/dictionary/apple

Beer, D. (2008). Social network(ing) sites... revisiting the story so far: A response to danah boyd \& Nicole Ellison. Journal of Computer-Mediated Communication, 13(2), 516-529.

Boyd, D. (2008). Why youth (heart) social network sites: The role of networked publics in teenage social life. In D. Buckingham (Ed.), Youth, Identity, and Digital Media (pp. 119-142). Cambridge, MA: MIT Press.

Boyd, D., \& Ellison, N. (2008). Social network sites: Definition, history, and scholarship. Journal of Computer-Mediated Communication, 13, 210-230.

Boyd, D., \& Heer, J. (2006). Profiles as conversation: Networked identity performance on Friendster. Proceedings of Thirty Ninth Hawai'i International Conference on System Sciences. Los Alamitos, CA: IEEE Press.

Cherry. (n.d.). Merriam-Webster Dictionary online. Retrieved from http://www.merriam-webster.com/dictionary/cherry

Choi, J. (2006). Living in Cyworld: Contextualizing Cy-Ties in South Korea. In A. Bruns \& J. Jacobs (Eds.), Use of Blogs (Digital Formations) (pp. 173-186). New York: Peter Lang.

DiMicco, J., \& Millen, D. (2007). Identity management: Multiple presentations of self in Facebook. Proceedings of the 2007 International ACM Conference on Supporting Group Work (pp. 383-386). New York: ACM.

Duggan, M. (2012, February 14). The demographics of social media users - 2012. Retrieved from http://www.pewInternet.org/Reports/2013/Social-mediausers.aspx 
Dwyer, C., Hiltz, S., \& Passerini, K. (2007). Trust and privacy concern within social networking sites: A comparison of Facebook and MySpace. Proceedings of Americas Conference on Information Systems 2007, Keystone, CO.

Ellison, N., Steinfield, C., \& Lampe, C. (2007). The benefits of Facebook "friends": Exploring the relationship between college students' use of online social networks and social capital. Journal of Computer Mediated Communication, 12 (3).

Ellison, N., Steinfield, C. and Lampe, C. (2009, May). Connection strategies: Relationship formation and maintenance on social network sites. Paper presented at the annual 14 meeting of the International Communication Association, Chicago, IL.

Ellison, N., Steinfield, C., \& Lampe, C. (2011). Connection strategies: Social capital implications of Facebook-enabled communication practices. New Media \& Society, 13(6), 873-892.

Ellison, N., Lampe, C., Steinfield, C, and Vitak, J. (2010). With a little help from my friends: How social network sites affect social capital processes. In Z. Papacharissi (Ed.) The Networked Self: Identity, Community, and Culture on Social Network Sites (in press). New York: Rutledge.

Facebook: Key facts. (n.d.). Retrieved from the Facebook Newsroom: http://newsroom.fb.com/Key-Facts

Field, A. (2013). Discovering Statistics Using IBM SPSS Statistics. 4th ed. Los Angeles, CA: Sage.

Flanagin, A., \& Metzger, M. (2001). Internet use in the contemporary media environment. Human Communication Research, 27(1), 153-181.

Gross, R., \& Acquisti, A. (2005). Information revelation and privacy in online social networks. Proceedings of Workshop on Privacy in Electronic Society (pp. 71-80). Alexandria, VA: ACM.

Hogan, B. (2008). Analyzing social networks via the Internet. In N. Fielding, R. Lee, \& G. Blank (Eds.), Sage Handbook of Online Research Methods (pp. 141-160). Thousand Oaks, CA: Sage.

Humphreys, S. (2009, July). The economies within an online social network market: A case study of Ravelry. In: Australia \& New Zealand Communication Association annual conference: Communication, Creativity and Global Citizenship, QUT Brisbane. Retrieved from http://eprints.qut.edu.au/26455/1/26455.pdf 
Joinson, A. N. (2008, April). Looking at, looking up or keeping up with people?: motives and use of facebook. In Proceedings of the Special Interest Group on ComputerHuman Interaction conference on Human Factors in Computing Systems (pp. 1027-1036). ACM.

Katz, E., \& Foulkes, D. (1962). On the use of the mass media as “escape”: Clarification of a concept. Public Opinion Quarterly, 26(3), 377-388.

Kaye, B. (2005). It's a blog, blog, blog world: users and uses of Weblogs. Atlantic Journal of Communication, 13(2), 73-95.

Kaye, B. (2010). Going to the Blogs: Toward the Development of a Uses and Gratifications Measurement Scale for Blogs. Atlantic Journal of Communication, 18(4), 194-210.

Kaye B. \& Johnson, T. (2002). Online and in the know: Uses and gratifications of the Web for political information. Journal of Broadcasting \& Electronic Media. 46(1) 54-71.

Korgaonkar, P., \& Wolin, L. (1999). A multivariate analysis of Web usage. Journal of Advertising Research, 39(2), 53-68.

Lampe, C., Ellison, N., \& Steinfield, C., (2006). A Face(book) in the crowd: Social searching vs. social browsing. Proceedings of Computer Support Cooperative Work (pp. 167-170). New York: ACM Press.

Lenhart, A., \& Madden, M. (2007). Teens, privacy, and online social networks: how teens manage their online identities and personal information in the age of MySpace. Pew Internet and American Life Project. Retrieved from: http://www.pewinternet.org/files/oldmedia/Files/Reports/2007/PIP_Teens_Privacy_SNS_Report_Final.pdf.pdf

Liben-Nowell, D., Novak, J., Kumar, R., Raghavan, P., \& Tomkins, A. (2005). Geographic routing in social networks. Proceedings Of The National Academy Of Sciences Of The United States Of America, 102(33), 11623-11628.

List of Social Networking Sites. (n.d.). Retrieved from Wikipedia: http://en.wikipedia.org/wiki/Social_networking_websites

McCarthy, C. (2010, Feb). The dark side of geo: Pleaserobme.com. CNet, Retrieved from http://news.cnet.com/8301-13577_3-10454981-36.html 
McQuail, D. (1984). With the benefits of hindsight: Reflections on uses and gratifications research. Critical Studies in Communication, 1, 177-193.

McQuail, D. (2000). McQuail's Mass Communication Theory (4th ed.) London: Sage Publications.

Papacharissi, Z. (2002). The Self Online: The Utility of Personal Home Pages. Journal of Broadcasting \& Electronic Media, 46(3), 346.

Papacharissi, Z., \& Mendelson, A. (2011). Toward a new(er) sociability: uses, gratifications and social capital on Facebook. In S. Papathanassopoulos (Ed.), Media Perspectives for the 21st Century (pp. 212-231). Routledge.

Papacharissi, Z. \& Rubin, A. (2000). Predictors of Internet use. Journal of Broadcasting \& Electronic Media, 44(2), 175-196.

Park, N., Kee, K., \& Valenzuela, S. (2009). Being Immersed in Social Networking Environment: Facebook Groups, Uses and Gratifications, and Social Outcomes. Cyberpsychology \& Behavior, 12(6).

Parker, B., \& Plank, R. (2000). A uses and gratifications perspective on the Internet as a new information source. American Business Review, 18(2), 43-49.

Perse, E., \& Dunn, D. (1998). The utility of home computers and media use: Implications of multimedia and connectivity. Journal of Broadcasting \& Electronic Media, 42(4), 435-456.

Quan-Haase, A., \& Young, A. (2010). Uses and gratifications of social media: A comparison of Facebook and Instant Messaging. Bulletin of Science, Technology \& Society, 30(5), 350-361.

Raacke, J., \& Bonds-Raacke, J. (2008). MySpace and Facebook: Applying the uses. CyberPsychology \& Behavior, 11(2), 169-174.

Ravelry About Us. (n.d.). Retrieved from Ravelry.com: http://www.ravelry.com/about

Ravelry Community Guidelines. (2009). Retrieved from Ravelry.com: http://www.ravelry.com/about/guidelines

Ravelry People Search. (n.d.). Retrieved from Ravelry.com: http://www.ravelry.com/people/search\#advanced=1 
Rodgers, S., Wang, Y., Rettie, R., Alpert, F. (2007). The Web Motivation Inventory: Replication, extension and application to Internet advertising. International Journal of Advertising, 26(4), 447-476.

Ruggiero, T. (2000). Uses and gratifications theory in the 21st century. Mass Communication \& Society, 3 (1), 3-37.

Sheldon, P. (2008). Student favorite: Facebook and motives for its use. Southwestern Mass Communication Journal, 23(2), 39-53.

Song, I., Larose, R, Eastin, M., \& Lin, C. (2004). Internet gratifications and Internet addiction: On the uses and abuses of new media. CyberPsychology \& Behavior. 7(4), 384-394.

Stacks, D. (2010). Primer of Public Relations Research. 2nd ed. New York, NY: Guilford Press.

Steinfield, C., DiMicco, J., Ellison, N., \& Lampe, C. (2009). Bowling online: Social networking and social capital within the organization. In Proceedings of the Fourth International Conference on Communities and technologies (pp. 245-254). New York: ACM.

Steinfield, C., Ellison, N., \& Lampe, C. (2008). Social capital, self-esteem, and use of online social network sites: A longitudinal analysis. Journal of Applied Developmental Psychology, 29 (6), 434-445.

Steinfield, C., Ellison, N., Lampe, C., \& Vitak, J. (2012). Online social network sites and the concept of social capital. In F. Lee, L. Leung, J. Qiu \& D. Chu (Eds.), Frontiers in New Media Research (pp. 115-131). New York: Routledge.

Stutzman, F. (2006). An evaluation of identity-sharing behavior in social network communities. Journal of the International Digital Media and Arts Association, 3 (1), 10-18.

Subrahmanyam, K., Reich, S., Waechter, N., \& Espinoza, G. (2008). Online and offline social networks: Use of social networking sites by emerging adults. Journal of Applied Developmental Psychology 29 (6), 420-433.

Tewksbury, D. \& Althaus, S. (2000) An examination of motivations for using the World Wide Web. Communication Research Report, 17(2), 127-138. 
Tong, S., Van Der Heide, B., Langwell, L., \& Walther, J. (2008). Too much of a good thing? The relationship between number of friends and interpersonal impressions on Facebook. Journal of Computer Mediated Communication, 13 (3), 531-549.

Urista, M., Dong, Q., \& Day, K. (2009). Explaining why young adults use MySpace and Facebook through uses and gratifications theory. Human Communication, 12(2), 215-229.

Walther, J., Van Der Heide, B., Kim, S., \& Westerman, D. (2008). The role of friends' appearance and behavior on evaluations of individuals on Facebook: Are we known by the company we keep? Human Communication Research, 34 (1), 28-49.

Wimmer, R., \& Dominick, J. (2011). Mass media research: An introduction-9/E. New York: McGraw-Hill. 


\section{Appendix A \\ Ravelry Moderator Permission}

Below is a screen shot of the Ravelry message traffic in which "Main 6" moderator Tammy Deloach (aka. sparkli) grants permission to post the same message on multiple discussion boards in support of the survey instrument for the master's thesis. She also outlines additional steps to take to annotate each post noting to readers that permission has been granted.

Although written in an informal style, Deloach's response clearly grants permission for what has been requested in the original message (also seen in screen shot) and meets the criteria outlines in the Ravelry Community Guidelines

(http://www.ravelry.com/about/guidelines). The informal nature of the response is beyond the investigator's control.

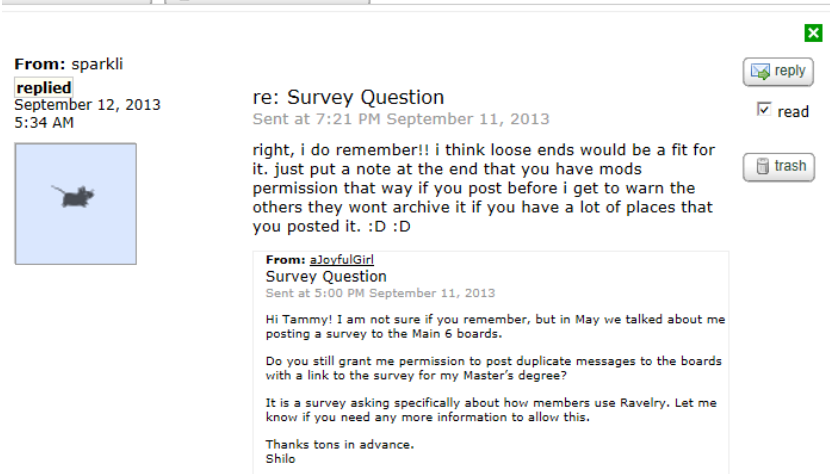




\section{Appendix B \\ Survey Recruitment Message}

You are invited to participate in a research study conducted by Shilo Weir, a graduate student in the School of Journalism at the University of Missouri-Columbia.

Responses to this study will help explain what motivates people to use Ravelry and Facebook. Therefore, please only volunteer for this study if you are a current member of both Ravelry and Facebook. The results from this study will contribute to a master's thesis.

Your participation is voluntary and your participation is anonymous. Your identity will in no way be connected to the data you provide. If you would like to volunteer your participation, please follow the link below that will take you to the online survey.

(Link to Survey Consent Form, followed by survey)

Thank you for your time and consideration,

Shilo Weir 


\section{Appendix C \\ Social Network Site Use Survey Instrument}

(Clicking the button at the bottom of the consent page sent the respondent to this page)

Please select the number that best represents your agreement or disagreement with each statement below.

I use Ravelry...

Strongly
disagree

Because it passes the time away.

To give me something to do to occupy my time.

To help pass the time when I am bored.

Because it relaxes me.

Because it allows me to unwind.

It helps me relax after school or work.

Because it is fun.

To entertain myself.

Because it is enjoyable entertainment.

To get information I need.

To share my knowledge and expertise.

To share information that may be of interested or useful to others.

To help me network with professional contacts.

Because it is helpful for my career.

To sell my patterns or products.

$$
\text { disagree }
$$

1

Strongly agree

$\begin{array}{llllll}1 & 2 & 3 & 4 & 5\end{array}$

$\begin{array}{llll}2 & 3 & 4 & 5\end{array}$

$\begin{array}{llllll}1 & 2 & 3 & 4 & 5\end{array}$

$\begin{array}{lllll}1 & 2 & 3 & 4 & 5\end{array}$

$\begin{array}{lllll}1 & 2 & 3 & 4 & 5\end{array}$

$\begin{array}{lllll}1 & 2 & 3 & 4 & 5\end{array}$

$\begin{array}{llllll}1 & 2 & 3 & 4 & 5\end{array}$

$\begin{array}{lllll}1 & 2 & 3 & 4 & 5\end{array}$

$\begin{array}{llllll}1 & 2 & 3 & 4 & 5\end{array}$

$\begin{array}{lllll}1 & 2 & 3 & 4 & 5\end{array}$

$\begin{array}{lllll}1 & 2 & 3 & 4 & 5\end{array}$

$\begin{array}{lllll}1 & 2 & 3 & 4 & 5\end{array}$

$\begin{array}{lllll}1 & 2 & 3 & 4 & 5 \\ 1 & 2 & 3 & 4 & 5 \\ 1 & 2 & 3 & 4 & 5\end{array}$


To feel like I am a part of a group.

Because it makes me feel less lonely.

When there is no one else to talk to.

To keep in touch with friends or family.

To communicate with distant friends.

Chatting to people I otherwise would lose contact with.

To meet new people.

Find groups of people who share my interests

Communicate with likeminded people

Because everyone else is doing it.

Because it is cool.

Because it's the thing to do.

To share my views.

To share personal information about myself.

To tell others about my opinions.

Out of habit.

Because I just like to play around on Ravelry

Because it is just something I do.

So I can forget about work, school or other things.

So I can get away from the rest of my family or other people.

So I can get away from what I am doing.

\section{1}

2

1

$\begin{array}{llll}2 & 3 & 4 & 5\end{array}$

1

$\begin{array}{llll}2 & 3 & 4 & 5\end{array}$

1

1

3

4

5

$\begin{array}{llll}2 & 3 & 4 & 5\end{array}$

$\begin{array}{lllll}1 & 2 & 3 & 4 & 5 \\ 1 & 2 & 3 & 4 & 5\end{array}$

$\begin{array}{lllll}1 & 2 & 3 & 4 & 5\end{array}$

$\begin{array}{lllll}1 & 2 & 3 & 4 & 5\end{array}$

$\begin{array}{lllll}1 & 2 & 3 & 4 & 5\end{array}$

$\begin{array}{lllll}1 & 2 & 3 & 4 & 5\end{array}$

$\begin{array}{lllll}1 & 2 & 3 & 4 & 5\end{array}$

$\begin{array}{llllll}1 & 2 & 3 & 4 & 5\end{array}$

$\begin{array}{lllll}1 & 2 & 3 & 4 & 5\end{array}$

$\begin{array}{llllll}1 & 2 & 3 & 4 & 5\end{array}$

$\begin{array}{lllll}1 & 2 & 3 & 4 & 5\end{array}$

$\begin{array}{lllll}1 & 2 & 3 & 4 & 5\end{array}$

$\begin{array}{lllll}1 & 2 & 3 & 4 & 5\end{array}$

$\begin{array}{lllll}1 & 2 & 3 & 4 & 5\end{array}$

$\begin{array}{lllll}1 & 2 & 3 & 4 & 5\end{array}$

$\begin{array}{lllll}1 & 2 & 3 & 4 & 5\end{array}$


(After completing the Likert scale portion of the use section, a button at the bottom of the page sent respondents to this section where they were asked to answer the following questions in their own words.)

Please answer the following questions in your own words:

1. Describe why you use Ravelry in your own words?

2. Why did you join Ravelry?

3. Why do you find Ravelry appealing?

(After completing the use portion of the survey, a button at the bottom of the page sent respondents to this section. Use Pattern information will be presented in drop-down menus.)

How long have you been a Ravelry member?

In the last 60 days, how many times have you logged in to Ravelry?

In the last 60 days, how often have you updated your Ravelry profile (about me, notebook, etc.)?

In the last 60 days, how many times have you communicated with others on Ravelry (sent messages, posted to a board, etc.)?

How many friends do you have in Ravelry?

How would you characterize how frequently you use Ravelry? (drop down menu listing: daily, weekly, monthly, occasionally (less often than monthly))

Complete the following statements (check all that apply):

I am more likely to use Ravelry... (all the time, around the holidays, when I am planning for special occasions)

I use Ravelry ... (the same amount year-round, more in the winter, more in the spring, more in the summer, more in the fall)

I use Facebook...

$\begin{array}{ll}\text { Strongly } & \begin{array}{l}\text { Strongly } \\ \text { disagree }\end{array} \\ \text { agree }\end{array}$

Because it passes the time away.

1

2

3

4

5

To give me something to do to occupy my

1

2

3

4

5 
time.

To help pass the time when I am bored.

$\begin{array}{llll}1 & 2 & 3 & 4\end{array}$

Because it relaxes me.

$\begin{array}{lllll}1 & 2 & 3 & 4 & 5\end{array}$

Because it allows me to unwind.

$\begin{array}{lllll}1 & 2 & 3 & 4 & 5\end{array}$

It helps me relax after school or work.

$\begin{array}{lllll}1 & 2 & 3 & 4 & 5\end{array}$

Because it is fun.

$\begin{array}{lllll}1 & 2 & 3 & 4 & 5\end{array}$

To entertain myself.

$\begin{array}{lllll}1 & 2 & 3 & 4 & 5\end{array}$

Because it is enjoyable entertainment.

$\begin{array}{llllll}1 & 2 & 3 & 4 & 5\end{array}$

To get information I need.

$\begin{array}{lllll}1 & 2 & 3 & 4 & 5\end{array}$

To share my knowledge and expertise.

$\begin{array}{lllll}1 & 2 & 3 & 4 & 5\end{array}$

To share information that may be of interested or useful to others.

$\begin{array}{lllll}1 & 2 & 3 & 4 & 5\end{array}$

To help me network with professional contacts.

$\begin{array}{lllll}1 & 2 & 3 & 4 & 5\end{array}$

Because it is helpful for my career.

$\begin{array}{lllll}1 & 2 & 3 & 4 & 5\end{array}$

To sell my patterns or products.

$\begin{array}{lllll}1 & 2 & 3 & 4 & 5\end{array}$

To feel like I am a part of a group.

$\begin{array}{lllll}1 & 2 & 3 & 4 & 5\end{array}$

Because it makes me feel less lonely.

$\begin{array}{lllll}1 & 2 & 3 & 4 & 5\end{array}$

When there is no one else to talk to.

$\begin{array}{lllll}1 & 2 & 3 & 4 & 5\end{array}$

To keep in touch with friends or family.

$\begin{array}{lllll}1 & 2 & 3 & 4 & 5\end{array}$

To communicate with distant friends.

1

$\begin{array}{llll}2 & 3 & 4 & 5\end{array}$

Chatting to people I otherwise would lose contact with.

$\begin{array}{lllll}1 & 2 & 3 & 4 & 5\end{array}$

To meet new people.

$\begin{array}{lllll}1 & 2 & 3 & 4 & 5\end{array}$

Find groups of people who share my interests 
Communicate with likeminded people

$\begin{array}{lllll}1 & 2 & 3 & 4 & 5 \\ 1 & 2 & 3 & 4 & 5 \\ 1 & 2 & 3 & 4 & 5 \\ 1 & 2 & 3 & 4 & 5 \\ 1 & 2 & 3 & 4 & 5 \\ 1 & 2 & 3 & 4 & 5 \\ 1 & 2 & 3 & 4 & 5 \\ 1 & 2 & 3 & 4 & 5\end{array}$

Out of habit.

Because I just like to play around on

Facebook.

Because it is just something I do.

$\begin{array}{lllll}1 & 2 & 3 & 4 & 5\end{array}$

$\begin{array}{lllll}1 & 2 & 3 & 4 & 5\end{array}$

So I can forget about work, school or other things.

$\begin{array}{lllll}1 & 2 & 3 & 4 & 5\end{array}$

So I can get away from the rest of my family or other people.

$\begin{array}{lllll}1 & 2 & 3 & 4 & 5\end{array}$

So I can get away from what I am doing. $\quad \begin{array}{lllllll}1 & 2 & 3 & 4 & 5\end{array}$

(After completing the Likert scale portion of the use section, a button at the bottom of the page sent respondents to this section where they were asked to answer the following questions in their own words.)

Please answer the following questions in your own words:

1. What is it about Facebook that makes it appealing?

2. What do you like most about Facebook?

3. What do you like the least about Facebook? 
(After completing the use portion of the survey, a button at the bottom of the page will send respondents to this section. Use Pattern information will be presented in drop-down menus.)

How long have you been a Facebook member?

In the last 60 days, how many times have you logged in to Facebook?

In the last 60 days, how often have you updated your Facebook profile (about me, notebook, etc.)?

In the last 60 days, how many times have you communicated with others on Facebook (sent messages, posted a status update, commented on a post, etc.)?

How many friends do you have in Facebook?

How would you characterize how frequently you use Facebook? (drop down menu listing: daily, weekly, monthly, occasionally (less often than monthly))

Complete the following statements (check all that apply):

I am more likely to use Facebook... (all the time, around the holidays, when I am planning for special occasions)

I use Facebook ... (the same amount year-round, more in the winter, more in the spring, more in the summer, more in the fall)

(After completing the use pattern portion of the survey, a button at the bottom of the page sent respondents to this section. Demographic information was presented in drop-down menus with the exception of the last question.)

Tell us about yourself...

Age?

Gender?

Highest grade-level completed?

Annual Income?

Employment Status?

(Select all that apply) What other social network sites are you a member? 


\section{Appendix D \\ Participant Consent}

Master's Thesis: A Uses and Gratifications Study of Niche Social Network Sites (RE:

\#1209074)

Welcome to the Ravelry Use Survey.

You are invited to participate in a research study conducted by a candidate for the Masters of Arts in Journalism Degree at the University of Missouri-Columbia. The project is called "Master's Thesis: A Uses and Gratifications Study of Niche Social Network Sites." The aim of this study is to understand what motivates you to use Ravelry. The results from this study will contribute to the completion of a master's thesis paper.

If you decide to participate, you will be asked to complete an online survey. The entire study should take approximately 30 minutes. Your participation is voluntary and you are free to withdraw at any time.

The data collected during this study will be kept confidential. Your participation is anonymous and no data you provide will be connected to you in any way. The principal researcher conducting this study is Shilo Weir. If you have any questions, you may contact her at E-mail: smw97b@mizzou.edu.

If you have any questions or concerns regarding the study and would like to talk to someone other than the researcher, contact MU Campus Institutional Review Board at (573) 882-9585 (reference: project \#1209074).

I have read the above information. Any questions I may have raised have been answered. By clicking the link provided below, I am stating that I am at least 18 years of age, a member of the site Ravelry.com, and that I consent to participate in the study.

(Link to Begin Survey)

Thank you so much for your time and participation in this endeavor. 


\section{Appendix E Deleted Scale Items}

\section{Deleted Items: Ravelry Use Motives}

I use Ravelry...

-Because it helps me relax after school or work.

-Because I just like to play around on Ravelry.

-Because it is just something I do.

-When there is no one else to talk to.

-To meet new people.

-To share personal information about myself.

-So I can forget about work, school or other things.

-So I can get away from the rest of my family or other people.

-So I can get away from what I am doing.

-Because it makes me feel less lonely.

\section{Deleted Items: Facebook Use Motives}

I use Facebook...

-When there is no one else to talk to.

-To entertain myself.

-Because I just like to play around on Facebook.

-So I can forget about work, school or other things.

-Because it allows me to unwind.

-To share my knowledge and expertise.

-To communicate with like-minded people.

-To share personal information about myself.

-Because it makes me feel less lonely.

-To feel like I am a part of a group.

-To meet new people.

-So I can get away from the rest of my family or other people.

-To find groups of people who share my interests.

-Because it is cool.

-To get information I need. 